\title{
Estudo Geoquímico e Petrológico dos Diques Máficos da Região de Candeias-Campo Belo-Santo Antônio do Amparo (MG), Porção Meridional do Craton São Francisco
}

\author{
Paulo César Corrêa da Costa ${ }^{1,3}$ (pccorrea@usp.br), Maurício Antônio Carneiro², \\ Wilson Teixeira ${ }^{3}$, Vicente Antonio Vitorio Girardi ${ }^{3}$, Hermínio Arias Nalini Júnior ${ }^{2}$, \\ Arildo Henrique de Oliveira ${ }^{2}$, Rinaldo Afrânio Fernandes ${ }^{4}$ \\ 'Departamento de Recursos Minerais - Instituto de Ciências Exatas e da Terra - UFMT \\ Av. Fernando Corrêa s/n, CEP 78060-900, Cuiabá, MT, BRA \\ ${ }^{2}$ Departamento de Geologia da Escola de Minas - UFOP, Ouro Preto, MG, BRA \\ ${ }^{3}$ Departamento de Mineralogia e Geotectônica - Instituto de Geociências - USP, São Paulo, SP, BRA \\ ${ }^{4}$ Departamento de Geologia - Instituto de Geociências - UFMG, Belo Horizonte, MG, BRA
}

Recebido em 21 de novembro de 2005; aceito em 02 de março de 2006

Palavras-chave: diques máficos, geoquímica, Craton São Francisco.

\section{RESUMO}

No Complexo Metamórfico Campo Belo, sul de Minas Gerais, ocorrem diques máficos divididos em quatro grupos em função de aspectos petrográficos, geoquímicos e tectônicos: Anfibolitos $\mathrm{A}_{1}$, Anfibolitos $\mathrm{A}_{2}$, Gabronoritos e Gabros. A grande maioria das amostras tem afinidade toleítica, porém os anfibolitos $\mathrm{A}_{2}$ e um gabronorito situam-se no campo cálcio-alcalino, sendo que alguns anfibolitos $\mathrm{A}_{1}$ e gabronoritos estão no limite dos campos. A análise dos diagramas geoquímicos mostrou que os tipos litológicos pertencem a quatro agrupamentos oriundos de magmas com diferentes graus de evolução, sendo os gabros os mais evoluídos (mg\# 0,18 - 0,23), seguindo-se os gabronoritos (mg\# 0,33 - 0,35), os anfibolitos A (mg\# 0,34 - 0,37) e os anfibolitos $A_{1}$ (mg\# 0,24 - 0,45). Sua comparação com modelos de fusão de mantos a granada e espinélio peridotito evidenciou o enriquecimento desses magmas progenitores, especialmente o da suíte gábrica, fato atribuível à fonte mantélica enriquecida e/ou contaminação crustal. Essa comparação aliada ao comportamento geoquímico diverso desses grupos em termos de elementos maiores, menores e traços indica a improbabilidade de cogeneticidade entre si. A comparação dos padrões de elementos traços entre os diques estudados e os enxames de Salvador, Carajás e Crixás-Goiás, pertencentes respectivamente aos Cratons São Francisco, Amazônico, e ao Bloco Arqueano de Goiás, sugere ambiente intracratônico.

Keywords: mafic dykes, geochemistry, São Francisco Craton.

\section{ABSTRACT}

Four groups of mafic dykes, distinguished by their petrographic, geochemical and tectonic features and designated as $\mathrm{A}_{1}$ amphibolites, $\mathrm{A}_{2}$ amphibolites, Gabbronorites and Gabbros, intrude the Campo Belo Metamorphic Complex in southern Minas Gerais. The majority of the samples have tholeiitic affinities, but the $\mathrm{A}_{2}$ amphibolites and one gabbronorite plot in the calc-alkaline field, and some $\mathrm{A}_{1}$ amphibolites and gabbronorites fall at the boundary of the two fields. The parental magmas of the four groups display different degrees of evolution: gabbros (mg\# $0.18-0.23$ ), gabbronorites (mg\# $0.33-0.35)$, $\mathrm{A}_{2}$ amphibolites (mg\# 0.34 - 0.37) and $A_{1}$ amphibolites (mg\# 0.24 - 0.45). Incompatible trace-element patterns, when compared with those of garnet and spinel peridotite sources, show enrichment of the original magmas, which mainly affected the parental melt of the gabbroic suite. This feature is attributed to either an enriched mantle source or crustal contamination. Major and trace element geochemistry indicates that the four groups are unrelated. Comparison of the trace-element patterns of the studied dykes with swarms from Salvador (São Francisco Craton), Carajás (Amazon Craton) and Crixás-Goiás (Archean Block of Goiás) suggest formation in an intracratonic environment. 


\section{INTRODUÇÃO}

O estudo geológico acerca do magmatismo de rochas máficas serve como parâmetro importante, para o conhecimento da evolução geodinâmica da crosta $\mathrm{e}$, ao mesmo tempo, fornece informações petrogenéticas sobre o comportamento e a evolução mantélica no tempo e no espaço (e.g. Halls, 1982; Halls e Fahrig, 1987; Sial, Oliveira, Choudhuri, 1987; Condie et al., 1987; Tarney e Weaver, 1987; Teixeira, 1990). Variadas são as combinações petrogenéticas do magmatismo máfico pré-cambriano (e.g. gabros, gabronoritos, anfibolitos etc), assim como diferenciados são os processos tectônicos superimpostos (e.g. metamorfismo e deformação). Estes processos, por sua vez, induzem assinaturas petrológicas, geoquímicas e isotópicas peculiares (Bellieni et al., 1995; Mazzucchelli et al., 1995; Corrêa Gomes et al., 1996; Mazzucchelli et al., 2000; Menezes Leal et al., 2000; Iacumin et al., 2001, 2003) dificultando a caracterização das feições petrogenéticas originais dos diques e/ou do enxame.

A geologia do magmatismo máfico do Craton São Francisco meridional, vem sendo investigada nos últimos tempos nos seus mais variados aspectos (e.g. Couto et al., 1983; Teixeira, 1989; Carneiro, 1990; Bellieni et al., 1991, 1995; Menezes et al., 1995; Pinese, 1997; Carneiro et al., 1998a; Corrêa da Costa, 1999; Corrêa da Costa et al., 2001; Carneiro et al., 2004). No presente trabalho, são discutidas as implicações petrológicas, geoquímicas e tectônicas dos eventos magmáticos máficos que afetaram a região de Candeias-Campo Belo-Santo Antônio do Amparo no contexto da evolução geológica da porção meridional do Craton São Francisco, além de comparações com enxames de diques máficos em outras regiões cratônicas.

\section{CONTEXTO GEOLÓGICO}

A porção meridional do Craton São Francisco (Figura 1) é constituída por um substrato siálico metamórfico de médio a alto grau, consolidado a partir do Mesoarqueano (Complexos Metamórficos Campo Belo, Bonfim, Bação e Belo Horizonte) que hospeda relíquias de seqüências supracrustais de idade neoarqueana (Supergrupo Rio das Velhas) e paleoproterozóica (Supergrupo Minas). Diversos eventos magmáticos (e.g. félsicos, máficos e ultramáficos) complementam o cenário geológico dessa região, abrangendo temporalmente o Paleoproterozóico - e.g. Teixeira et al. (2000). Petrograficamente, tais complexos metamórficos são constituídos por gnaisses e granitóides migmatizados e intrusivas máficasultramáficas acamadadas (Carneiro et al., 1996).

O estudo geológico do substrato siálico dessa região tem sido intensificado a partir de dados analíticos geoquímicos e isotópicos, destacando-se os resultados obtidos nos complexos metamórficos Bonfim e Campo Belo (Teixeira, 1982; Teixeira et al., 1998; Carneiro et al., 1996, 1998b; Machado e Carneiro 1992; Pinese, 1997; Noce, 1995; Carvalho Jr. et al., 1997; Oliveira et al., 1998; Carneiro et al., 2004). No caso do Complexo Metamórfico Campo Belo (Figura 2), os seus litotipos dominantes foram enquadrados em seis suítes litotectônicas assim discriminadas: Gnáissica, Anfibolítica, Ultramáfica, Granitóide, Gabronorítica e Gabróica (Corrêa da Costa, 1999; Fernandes, 2001). A evolução crustal deste Complexo teve início no Mesoarqueano, há $3,2 \mathrm{Ga}$ atrás, conforme dados geocronológicos U-Pb SHRIMP em cristais de zircões e determinações Sm$\mathrm{Nd}, \mathrm{Rb}-\mathrm{Sr}$ e $\mathrm{Pb}-\mathrm{Pb}$ em rocha total (e.g. Teixeira et al., 1998). Durante o Neoarqueano vários episódios tectonomagmáticos ocorreram, produzindo o espessamento crustal e aglutinação dos embriões siálicos primitivos em decorrência do Evento Rio das Velhas, datado entre 2,78 e 2,70 Ga (Machado e Carneiro, 1992). Durante o Paleoproterozóico desenvolveu-se na extremidade meridional do paleocontinente arqueano, o cinturão Mineiro (Teixeira et al., 2000; Noce et al., 2000), ao qual se vincula importante evento plutônico máfico-félsico e diques máficos - estes últimos formando enxames de diques intrusivos no substrato da porção Meridional do Craton São Francisco. O conjunto de diques máficos da região de Lavras-Bom Sucesso (MG), a sudeste da região de Campo Belo, relaciona-se a esse magmatismo. Pinese (1997) estudou-o e classificou-o em dois subgrupos:

\section{Básico Norítico (2,65 Ga);}

2. Básico (1,9 Ga).

No caso dos diques máficos estudados no presente trabalho admite-se, em função das semelhanças geológicas, petrográficas, tectônicas (mesma direção de intrusão) e geoquímicas idade de intrusão semelhante à do grupo básico estudado por Pinese (1997) em Lavras - MG (Figura 1).

\section{GEOLOGIA E CARACTERÍSTICAS PETROGRÁFICAS}

O magmatismo máfico em estudo compreende rochas das suítes Anfibolítica, Gabronorítica e Gábrica que afloram entre as cidades de Candeias, Campo Belo e Santo Antonio do Amparo, Estado de Minas Gerais, no contexto tectônico policíclico da borda meridional do Craton São Francisco (e.g. Corrêa da Costa, 1999) destacado na Figura 2. Apesar do significativo intemperismo químico, imposto à região em estudo, é possível localizar, com freqüência, afloramentos dessas rochas em bom estado de conservação, onde foram coletadas as amostras do presente estudo. Mesmo na ausência de afloramentos, é possível observar o contraste de solos 


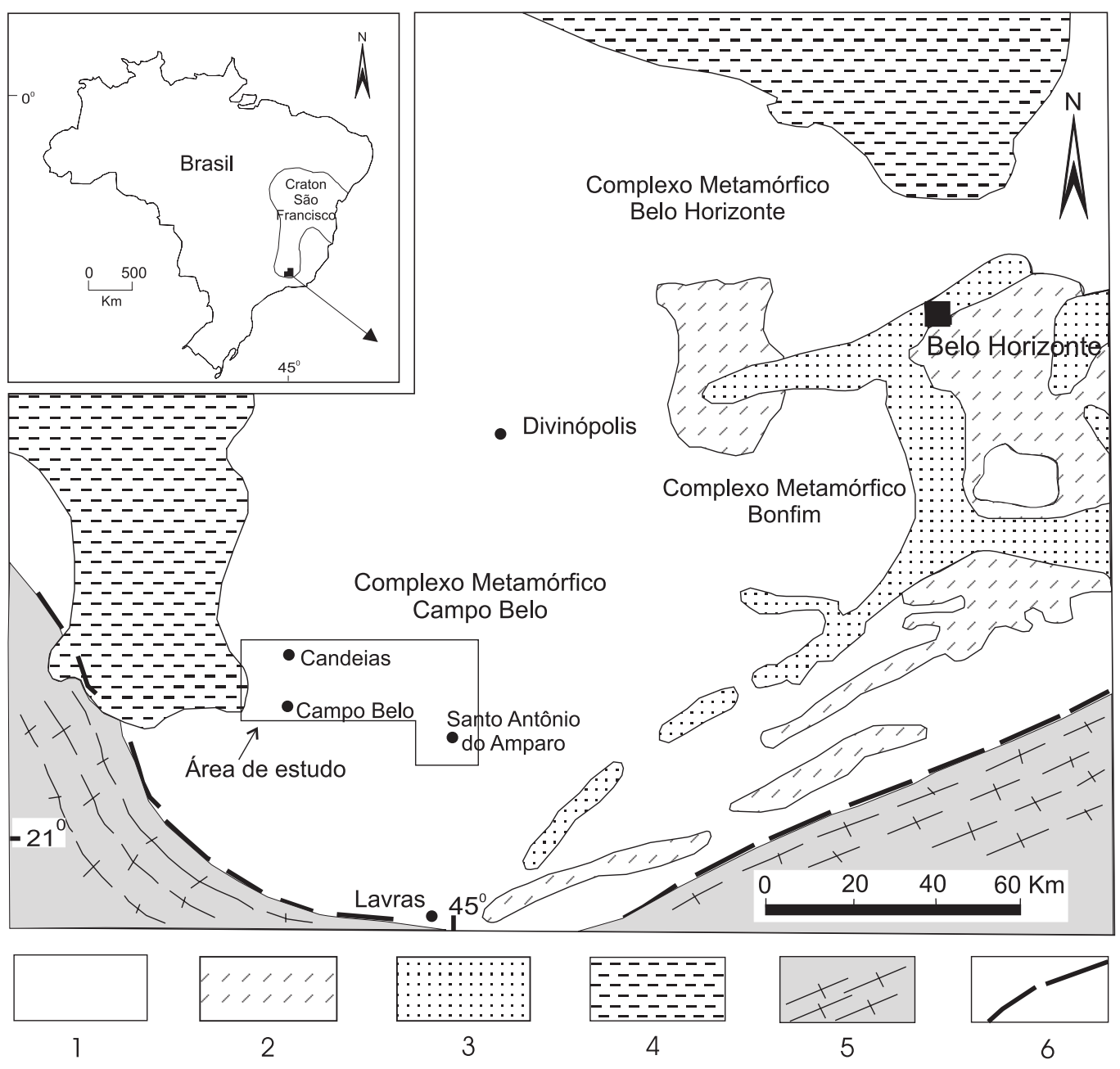

Figura 1. Esboço geológico do segmento meridional do Craton São Francisco, mostrando a localização da área de estudo, os complexos metamórficos (Campo Belo, Belo Horizonte e Bonfim) e seqüências supracrustais (mod. de Teixeira et al., 1998). 1. Terrenos de alto a médio grau metamórfico (arqueanos). 2. "Greenstone belts" arqueanos. 3. Supergrupo Minas (Paleoproterozóico). 4. Grupo Bambuí (Neoproterozóico). 5. Cinturões móveis neoproterozóicos. 6. Limites tectônicos do Craton São Francisco.

rosados, provenientes da alteração dos gnaisses, intercalados com faixas de solo vermelho, orientadas na direção NW, resultantes da decomposição dos litotipos máficos, diagnósticas da potência e volume do magmatismo que caracterizam um enxame de diques de expressão regional.

Em termos gerais, as principais diferenças petrográficas entre os vários litotipos envolvidos neste estudo (anfibolito, gabronorito e gabro), referem-se à presença predominante de hornblenda castanha, às texturas metamórficas e estruturas bandadas dos anfibolitos, contrastado com a mineralogia e textura ígnea e a ausência de deformação dos gabronoritos e gabros.

As rochas da Suíte Anfibolítica foram separadas em dois grupos, conforme o seu modo de ocorrência. O primeiro grupo compreende os litotipos encontrados na forma boudins encravados nos gnaisses regionais que, provavelmente, representam antigos corpos intrusivos (diques) deformados e desmembrados, num dos vários eventos tectonotermais superimpostos à região (e.g. Oliveira e Carneiro, 2001). Esse tipo petrográfico, abundante na área, de agora em diante, será denominado de Anfibolito $\mathrm{A}_{1}$. O segundo grupo compreende os litotipos encontrados na forma de diques cortando a foliação das rochas gnáissicas do substrato siálico. São pouco deformados, contínuos, e restringem-se a uma região distante cerca de $3 \mathrm{~km}$ de Campo Belo. A esse tipo petrográfico será atribuída a designação de Anfibolito $\mathrm{A}_{2}$.

As rochas das Suítes Gabronorítica e Gabróica distribuem- 


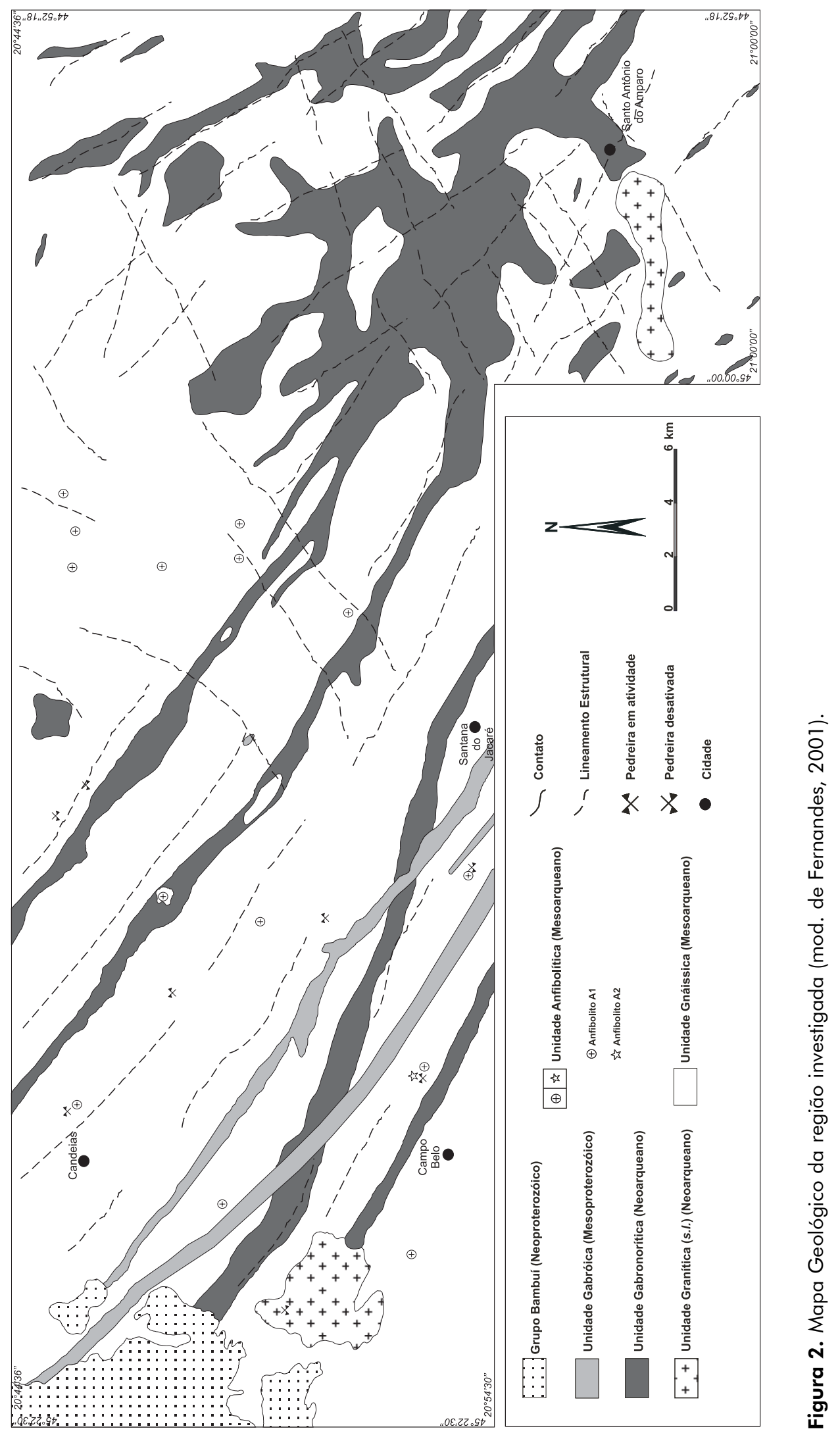


se como diques orientados preferencialmente na direção NW-SE (Figura 2) e são recobertos pelos sedimentos neoproterozóicos do Grupo Bambuí, na porção noroeste da área. Nota-se uma ligeira variação na orientação geral dos diques dessas duas suítes ígneas. Enquanto que os diques gabronoríticos têm direção preponderante N65-70W, os diques gabroícos, orientam-se na direção N50-55W (Figura 3). Essas duas gerações de diques exibem contatos discordantes com as rochas encaixantes, são verticais a subverticais e com espessuras variando de metros a centenas de metros e extensão quilométrica (Figura 2). As descrições petrográficas das suítes são discriminadas a seguir.

\section{Anfibolitos}

Apesar das diferentes formas de ocorrência das rochas da Suíte Anfibolítica anteriormente citadas (Anfibolitos $\mathrm{A}_{1} \mathrm{e}$ Anfibolitos $\mathrm{A}_{2}$ ), essas rochas apresentam características petrográficas bastante semelhantes. Entretanto, os anfibolitos $A_{1}$ apresentam-se mais deformados e têm maior quantidade de hornblenda que os anfibolitos $A_{2}$. Trata-se de variações texturais do tipo granoblástico, lepidoblástico e nematoblástico. $\mathrm{O}$ anfibolito tem uma paragênese principal formada essencialmente por hornblenda (50 a 70\%), plagioclásio (20 a 30\%) e em menor quantidade ortopiroxênio e clinopiroxênio (5 a 10\% do volume total da rocha). A paragênese secundária (retrometamórfica) é representada por biotita, sericita, epidoto e clorita. Quartzo (cerca de 5\%) e a biotita (2\%) ocorrem subordinadamente. Como minerais acessórios têm-se apatita, zircão, titanita e opacos. A sericita é produto de alteração, geralmente de plagioclásio. A microclina é muito rara, apresentando-se de maneira intersticial.

\section{Gabronoritos}

Os gabronoritos exibem textura ofítica a subofítica e intercrescimentos mimerquítico e granofírico. Sua mineralogia é composta essencialmente, por plagioclásio (50 a 55\%), hiperstênio (10 a 15\%) e augita (15 a $20 \%)$. O quartzo $(5$ a $10 \%)$ forma por vezes intercrescimentos gráficos. A sericita é produto de alteração, geralmente de plagioclásio. Opacos, biotita, apatita, epídoto e zircão são acessórios.

\section{Gabros}

Os gabros exibem textura ofítica, subofítica e intergranular. A sua mineralogia é composta por plagioclásio (50 a 60\%) e augita (20 a $40 \%)$ e, em menor quantidade, por quartzo (5\%) e hornblenda (até 3\%). Opacos, biotita, apatita e zircão são acessórios, e clorita, epídoto, sericita e carbonato produtos de alteração de plagioclásios e piroxênios. Tem-se, portanto, que as principais diferenças petrográficas entre essas duas suítes consistem no fato dos gabronoritos apresentarem ortopiroxênio e intercrescimentos granofíricos (quartzofeldspática), enquanto que os gabros têm maior quantidade de minerais opacos e não possuem ortopiroxênio.

\section{MÉTODOS ANALÍTICOS}

As amostras selecionadas para análises geoquímicas foram britadas e pulverizadas no Laboratório de Preparação de Amostras (LOPAG) do Departamento de Geologia da Escola de Minas da Universidade Federal de Ouro Preto. As análises químicas para determinação das concentrações de elementos maiores, menores e traços, foram realizadas em dois laboratórios distintos (Activation Labs. Ontário, Canadá e Laboratoire de Geochimie da Ecole de Mines de Saint Etienne, na França). Amostras em duplicata, analisadas nesses laboratórios, demonstraram a acuidade dos resultados obtidos, que estão apresentados na Tabela 1. As
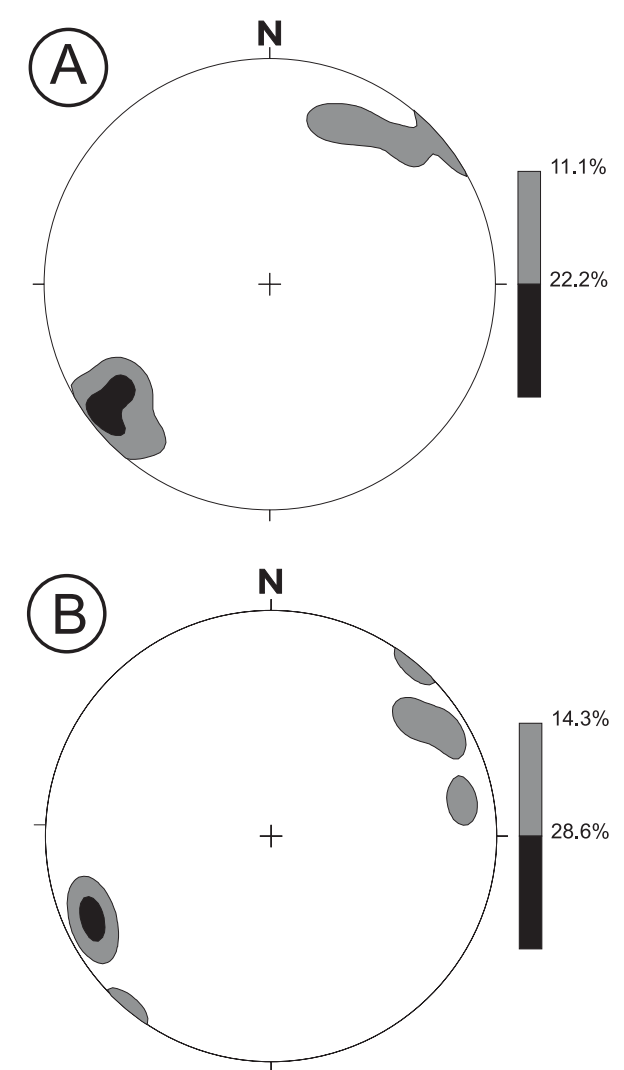

Figura 3. A) Diagrama estereográfico representando a projeção polar dos diques de composição gabronorítica. Número de medidas: 14; máximo: 050/76. B) Diagrama estereográfico representando a projeção polar dos diques de gabro. Número de medidas do plano: 12; máximo: 065/78. 
concentrações de elementos maiores e menores foram obtidas através dos métodos de fluorescência de raios - X e espectrometria de emissão atômica com plasma de acoplamento indutivo (ICP), enquanto que os elementos terras raras (ETR), mais $\mathrm{Cr}$, $\mathrm{Rb}$ e $\mathrm{Sc}$ foram determinados por Ativação Neutrônica. Os erros analíticos para os elementos maiores, são entre 2 e $5 \%$ e, para os elementos traços, são inferiores a $10 \%$. $\mathrm{O} \mathrm{Fe}_{2} \mathrm{O}_{3} \mathrm{~T}$ foi determinado pela análise química como ferro total e, o FeO foi calculado assumindo a razão $\mathrm{Fe}_{2} \mathrm{O}_{3} / \mathrm{FeO}=0,15$.

\section{GEOQUÍMICA DE ROCHA TOTAL}

Para avaliar a possibilidade de mobilização de elementos químicos dos litotipos máficos foram utilizados os diagramas das razões de proporções moleculares (MPR) de acordo com Pearce (1968) e Beswick (1982) entre outros. Os diagramas obtidos com os dados químicos dos litotipos metamorfizados mostraram que, de modo geral, não ocorreram mobilizações significativas, conservando-se as tendências ígneas originais.

O diagrama AFM (Irvine e Baragar, 1971; Figura 4) mostra que os litotipos estudados têm predominantemente afinidade toleítica, com típico enriquecimento em FeOt em relação aos álcalis e ao $\mathrm{MgO}$, porém os anfibolitos $\mathrm{A}_{2}$ e um gabronorito situam-se no campo cálcio-alcalino, sendo que alguns anfibolitos $\mathrm{A}_{1}$ e gabronoritos estão no limite dos campos.

Na Figura 5 de Le Bas et al. (1986) verifica-se que todos os anfibolitos $\mathrm{A}_{1}$ e a maioria dos gabros são quimicamente classificados como basaltos. Alguns destes estão nos limites desse campo com o de basanito/tefrito, dois deles encontram-se nesse campo e um no de traquibasalto. Os gabronoritos situam-se predominantemente no campo dos andesitos basálticos, e os anfibolitos $\mathrm{A}_{2}$ se posicionam na região limítrofe dos campos de andesito basáltico, andesito e traquiandesito basáltico.

Em termos composicionais, as principais diferenças entre os litotipos estudados ficam mais evidentes quando os resultados são tratados em diagramas de variação utilizando o número de magnésio mg\# $[\mathrm{MgO} /(\mathrm{MgO}+\mathrm{FeOt})$ em razão molar] como índice de diferenciação (Figuras 6 e 7). O valor de mg\# varia de 0,18 - 0,23 para os gabros, 0,33 - 0,35 para os gabronoritos, 0,34 - 0,37 para os anfibolitos $\mathrm{A}_{2}$ e 0,24 - 0,45 para os anfibolitos $\mathrm{A}_{1}$. Tais valores são típicos de líquidos basálticos evoluídos. Magmas basálticos primários derivados de peridotitos mantélicos teriam normalmente valores de $\mathrm{mg \#}$ entre 0,74 - 0,80 (Jaques e Green, 1979; Jaques e Green, 1980; Takahashi e Kushiro, 1983; Bossi et al., 1993).

Nos diagramas de variação das Figuras 6 e 7, observa-se que os anfibolitos $\mathrm{A}_{1}$ apresentam um aumento nas concentrações de $\mathrm{TiO}_{2}, \mathrm{FeOt}, \mathrm{MnO}, \mathrm{K}_{2} \mathrm{O}, \mathrm{P}_{2} \mathrm{O}_{5}, \mathrm{Zr}, \mathrm{V}, \mathrm{Y}$ e Yb e, uma diminuição dos teores de $\mathrm{Cr}$ e $\mathrm{Ni}$ com a progressão

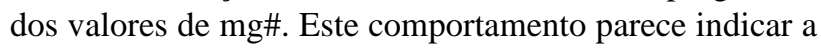

atuação de um processo de cristalização fracionada iniciando-se com a cristalização de olivina até cerca de 0,30 mg\# e após este valor tem-se a cristalização de clinopiroxênio e plagioclásio. Os anfibolitos $A_{2}$ apresentam distribuição muito concentrada e, portanto, não mostram clara tendência evolutiva em termos dos elementos maiores e traços. Entretanto, fica evidente que para um mesmo valor de $\mathrm{mg \#}$ eles são mais pobres em $\mathrm{CaO}, \mathrm{FeO}_{\mathrm{t}}, \mathrm{MnO}, \mathrm{Cr}, \mathrm{V} \mathrm{e} \mathrm{Yb}$, e mais ricos em $\mathrm{SiO}_{2}, \mathrm{~K}_{2} \mathrm{O}$ e $\mathrm{Al}_{2} \mathrm{O}_{3}$ que os anfibolitos $\mathrm{A}_{1}$, fato que sugere ausência de cogeneticidade.

Nos gabros, que constituem a suíte mais evoluída da área, com a diminuição dos teores de mg\# ocorre diminuição de $\mathrm{CaO}, \mathrm{Al}_{2} \mathrm{O}_{3}, \mathrm{Cr}$ e Ni e aumento de $\mathrm{SiO}_{2}, \mathrm{FeO}_{\mathrm{t}}$, e elementos traços incompatíveis. Observa-se na Figura 6 uma dispersão maior de $\mathrm{K}_{2} \mathrm{O}, \mathrm{P}_{2} \mathrm{O}_{5}$ e $\mathrm{SiO}_{2}$ nos gabros em relação às demais rochas face provavelmente à maior mobilidade desses elementos nessa suíte.

Os gabronoritos, à semelhança dos anfibolitos $\mathrm{A}_{2}$ ocupam uma área muito restrita nos diagramas de variação, e por isso não se pode detectar tendência evolutiva. $\mathrm{O}$ comportamento geral dos elementos em relação ao mg\# permite sugerir-se que os quatro grupos de rochas parecem pertencer a grupos distintos e nesse caso teriam evoluções magmáticas independentes. Tal discussão será retomada com a análise dos outros diagramas geoquímicos.

A Figura 8 apresenta o diagrama multi-elementar de composição média para as rochas das suítes anfibolítica, gabronorítica e gábrica, normalizado para o manto primitivo segundo os valores de McDonough e Sun (1995). Observase nesta figura que os anfibolitos $\mathrm{A}_{1}$ apresentam concentrações mais baixas de elementos litófilos de grande raio iônico (LILE - K, Rb e Ba) e mais elevadas para os elementos $\mathrm{Ti}, \mathrm{Y}$ e $\mathrm{Yb}$, quando comparados com os anfibolitos $\mathrm{A}_{2}$. Os gabros apresentam um padrão geoquímico mais enriquecido em toda gama de elementos, quando comparados com os gabronoritos. As anomalias, negativa de $\mathrm{Nb}$ e positiva de $\mathrm{Ce}$, são comuns a todos os grupos.

Os padrões geoquímicos da composição média dos elementos terras raras (ETR), normalizado para os valores de Boynton (1984), estão representados na Figura 9. Nesta figura é possível observar que os anfibolitos $A_{1}$ são mais empobrecidos nos elementos terras raras leves (ETRL) e enriquecidos nos elementos terras raras pesados (ETRP), quando comparados com os anfibolitos $\mathrm{A}_{2}$. Os gabros são expressivamente mais enriquecidos em toda gama dos elementos terras raras em comparação a todas as outras suítes.

O padrão dos elementos incompatíveis das rochas investigadas também foi comparado com os basaltos da cadeia meso-oceânica (MORB) e ilha oceânica (OIB; e.g. McDonough e Sun, 1995; Figura 10). Nota-se que os gabros são os mais enriquecidos, e seu padrão tem semelhanças com OIB, principalmente no que concerne aos teores de 


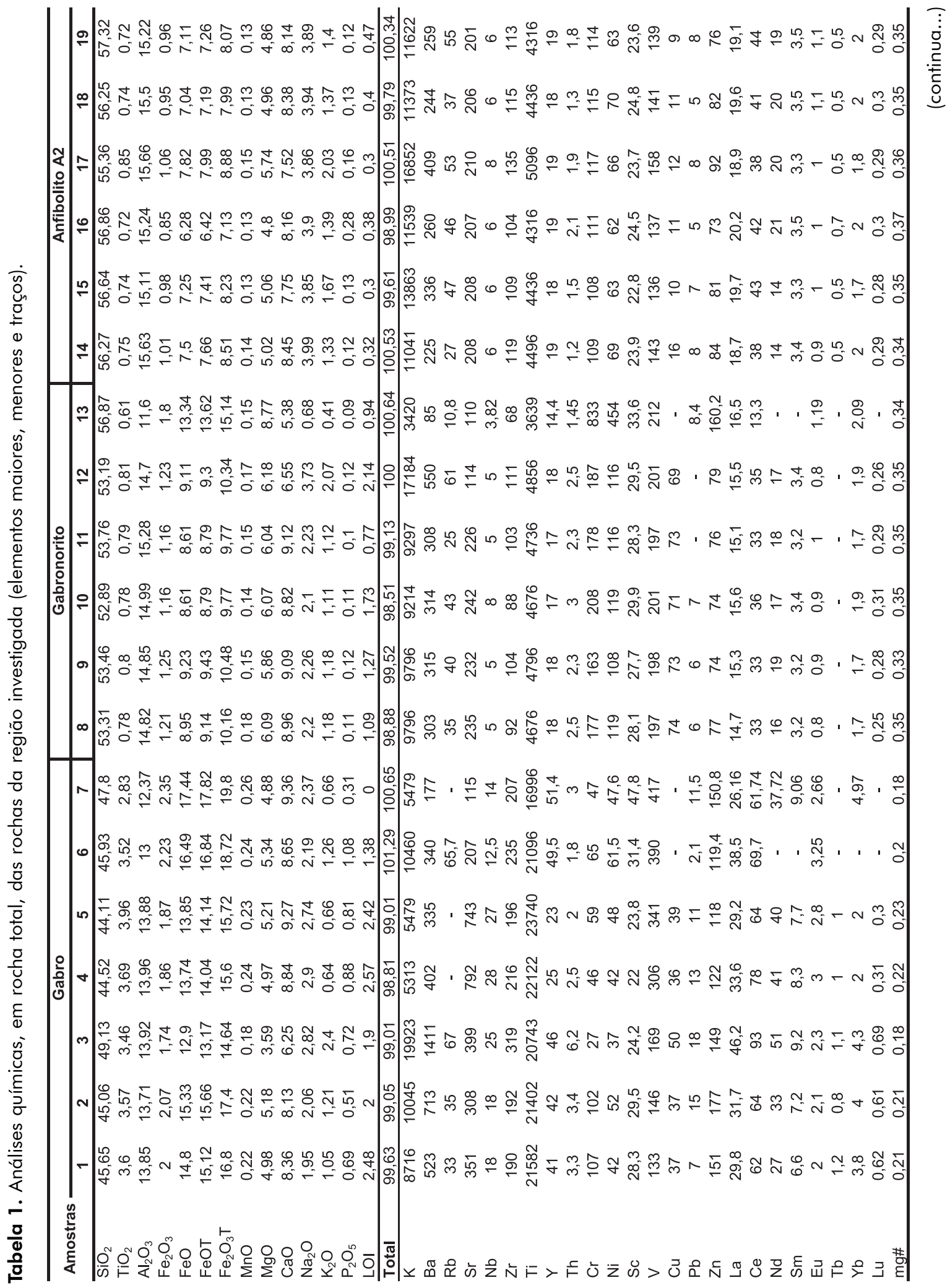




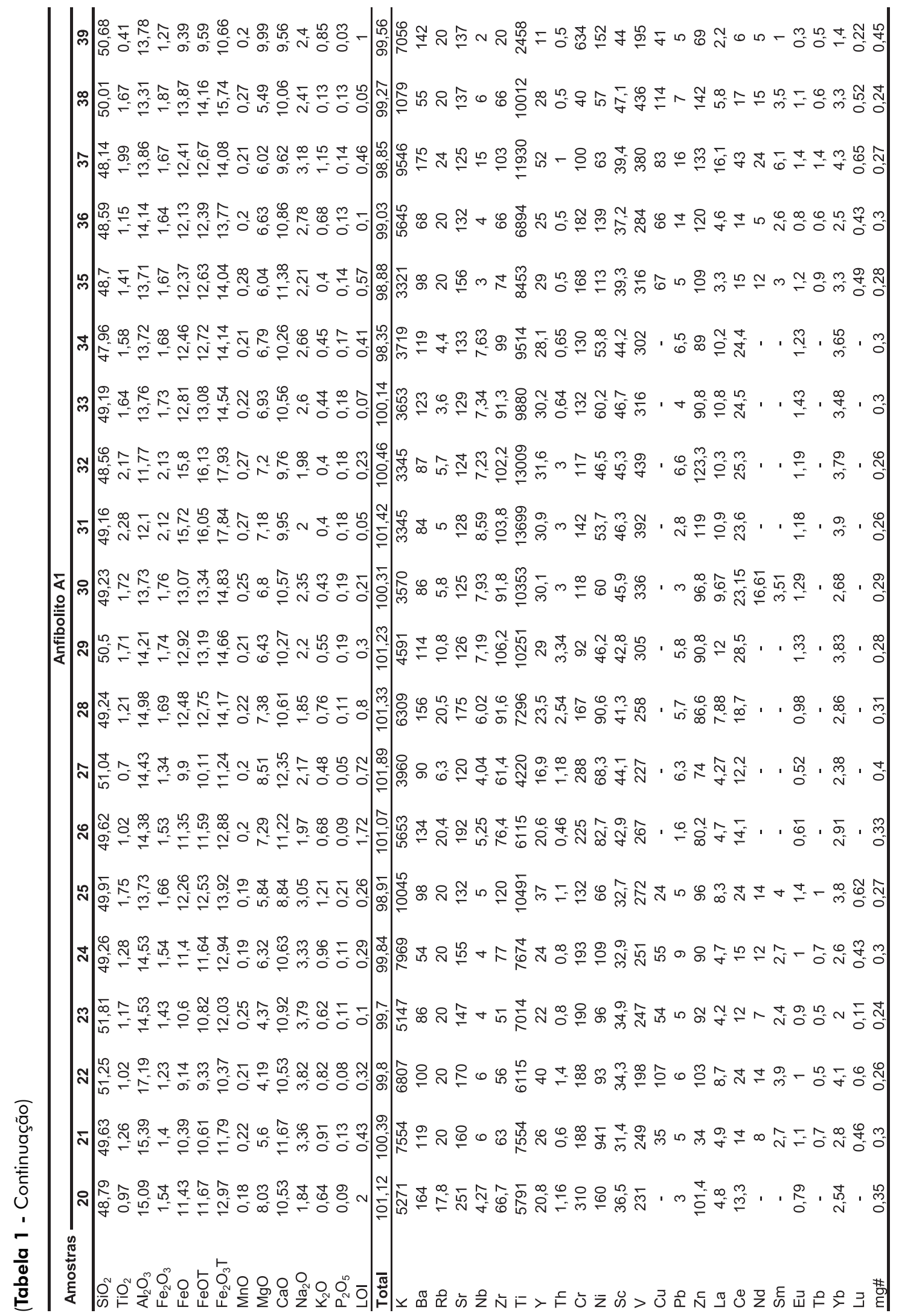




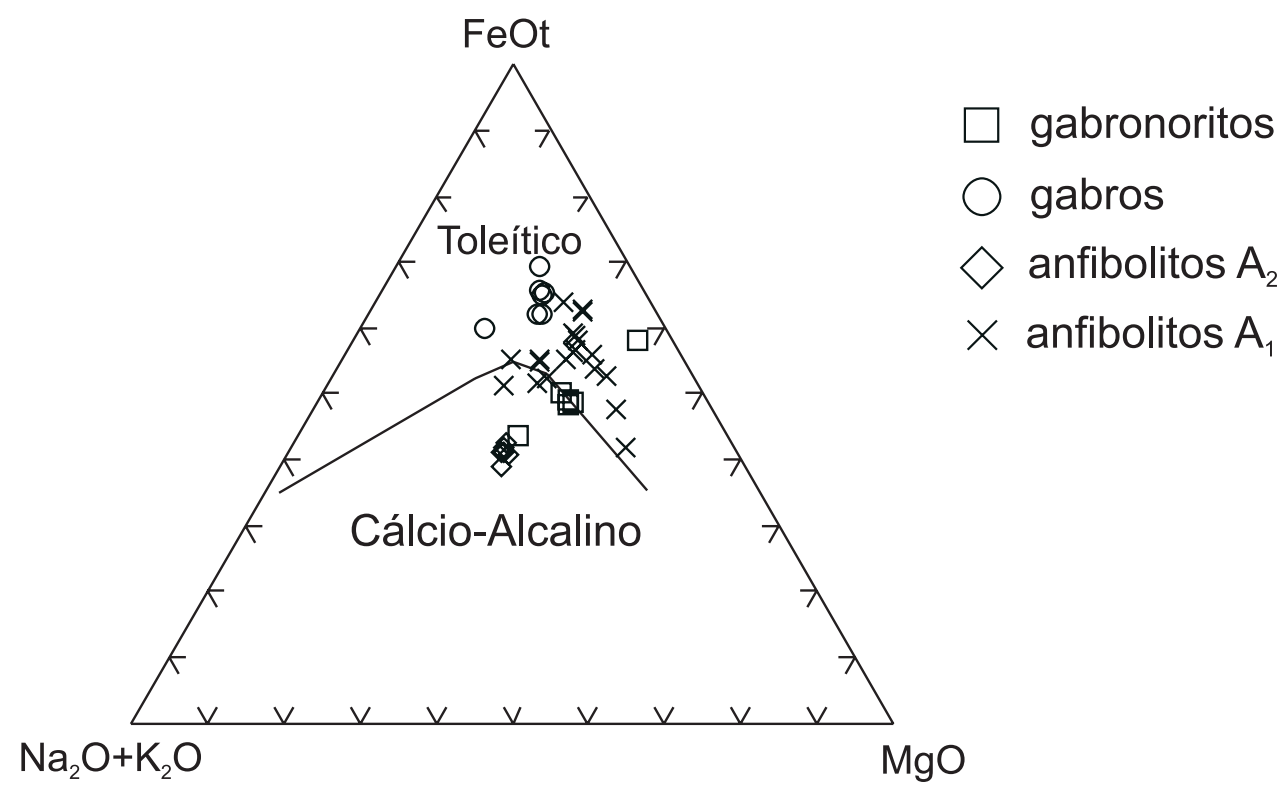

Figura 4. Diagrama AFM $\left(\mathrm{Na}_{2} \mathrm{O}+\mathrm{K}_{2} \mathrm{O}\right)$ - $\mathrm{FeOt}-\mathrm{MgO}$, segundo a proposta de Irvine e Baragar (1971).

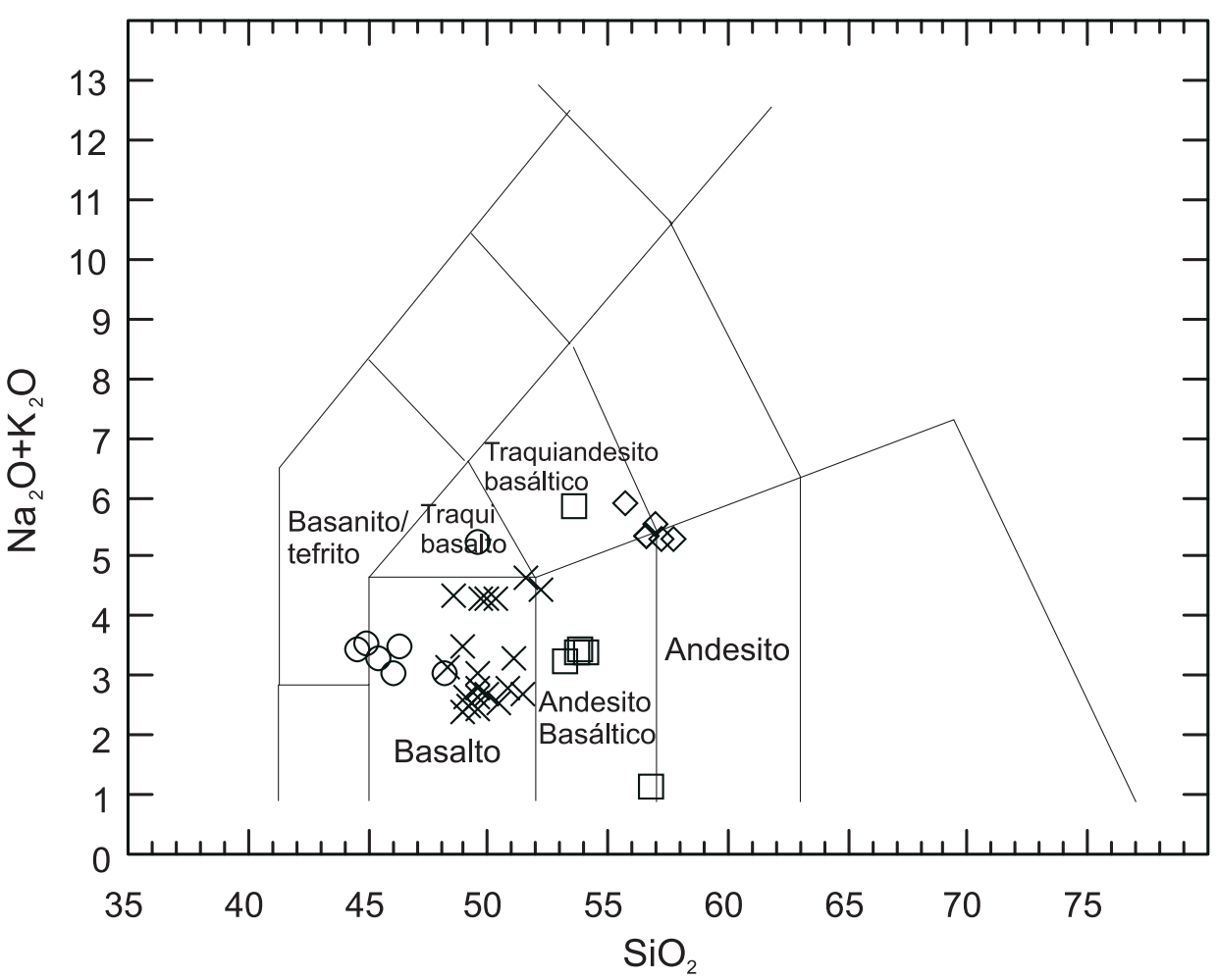

Figura 5. Diagrama de classificação geral dos litotipos estudados, de acordo com La Bas (1986). Símbolos como na Figura 4. 

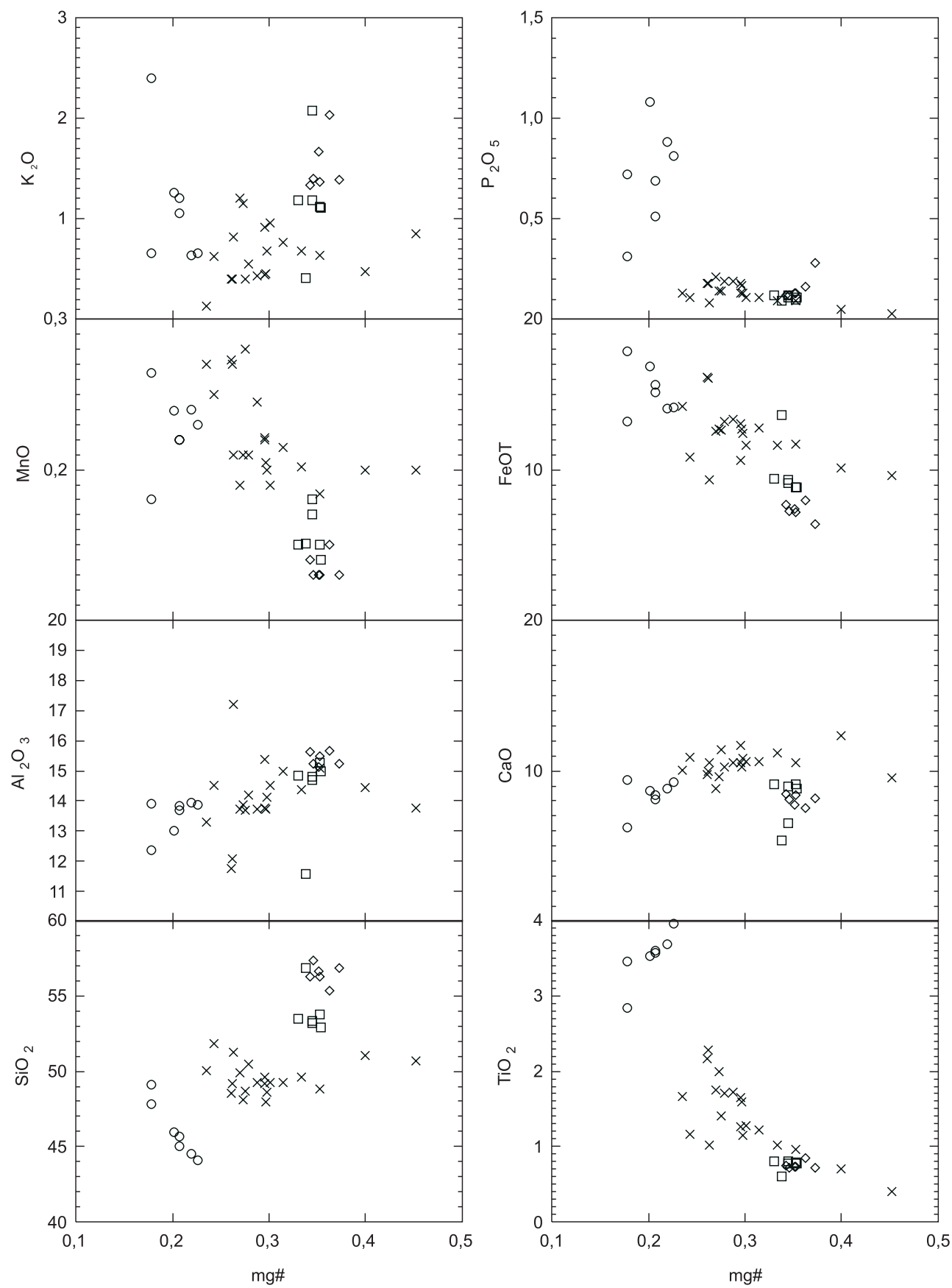

Figura 6. Diagramas de variação (mg\# vs. óxidos) dos litotipos estudados. Símbolos como na Figura 4. 

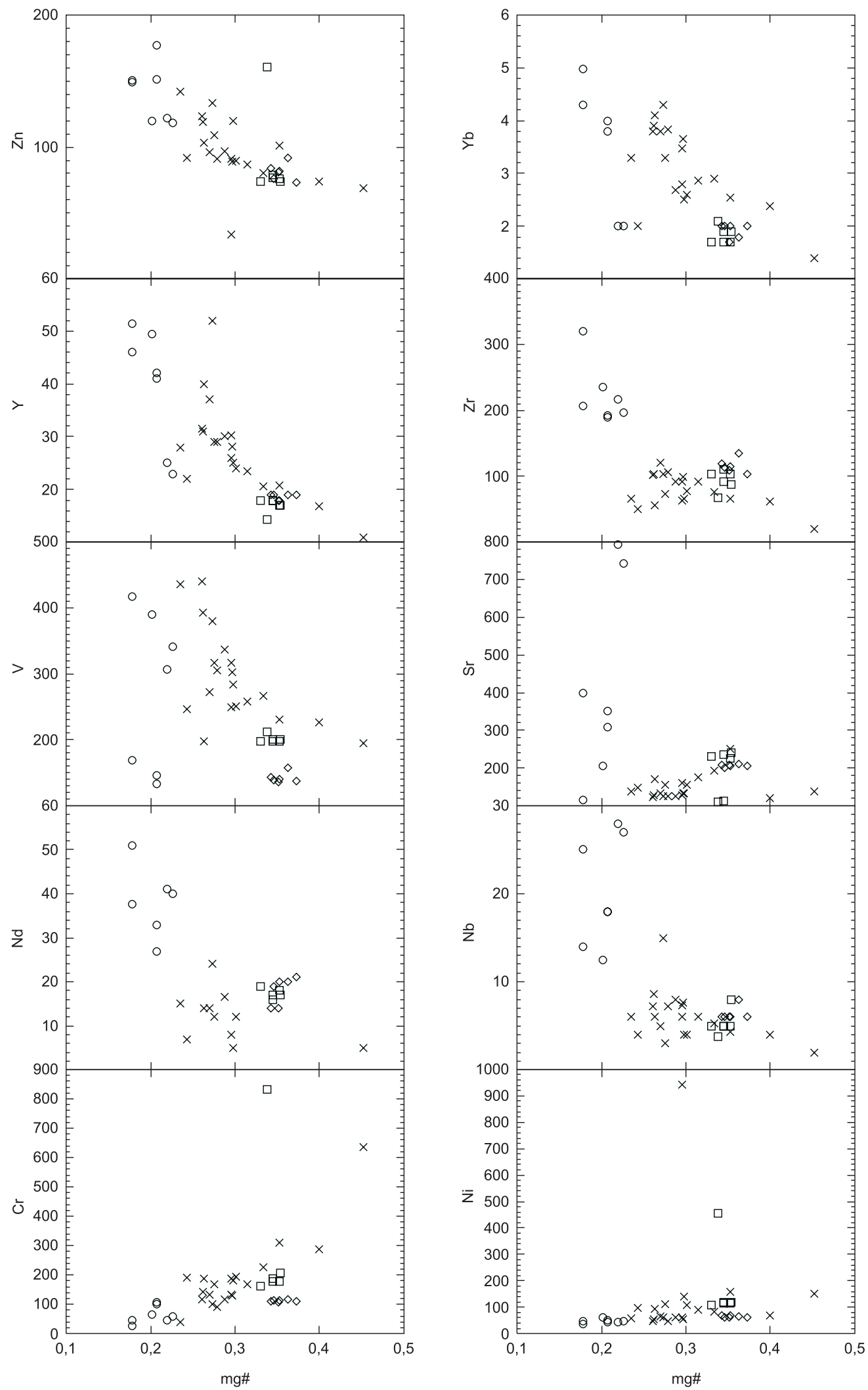

Figura 7. Diagramas de variação (mg\# vs. elementos traços) dos litotipos estudados. Símbolos como na Figura 4. 
terras raras leves e intermediárias. Os LILE e terras raras pesadas atingem alto nível de enriquecimento. A anomalia negativa de $\mathrm{Nb}$, comum a todas as suítes, é freqüentemente interpretada como uma característica de ambiente continental. Os gabronoritos têm composição intermediária entre os padrões OIB e E-MORB, estando mais próximos dos E-MORB, excetuando-se os elementos LILE que chegam a superar os níveis de OIB. Os anfibolitos $\mathrm{A}_{2}$ têm padrão intermediário entre OIB e E-MORB e são mais enriquecidos em LILE e La que os anfibolitos $\mathrm{A}_{1}$, cujo campo de variação é o mais largo de todos, abrangendo desde teores muito empobrecidos até enriquecidos.

Os padrões geoquímicos identificados através dos diagramas das Figuras 8, 9 e 10, reforçam a sugestão deduzida através das Figuras 6 e 7, em relação à presença de quatro agrupamentos geoquímicos distintos, representados pelos anfibolitos $\mathrm{A}_{1}, \mathrm{~A}_{2}$, gabronoritos e gabros.

\section{CARACTERÍSTICA DA FONTE}

Com o objetivo de avaliar a origem da fonte e a interrelação dos diversos litotipos máficos, foi testado o processo magmático admitindo-se diferentes graus de fusão a partir de uma fonte homogênea.

Os padrões de elementos traços dos anfibolitos, gabronoritos e gabros foram comparados com modelos de fusões em equilíbrio correspondente a 10,15, 25 e $30 \%$ de fontes mantélicas primitivas, sendo uma fonte com composição do tipo granada peridotito e outra do tipo espinélio peridotito (McDonough e Sun, 1995; Figuras 11 e 12). Os coeficientes

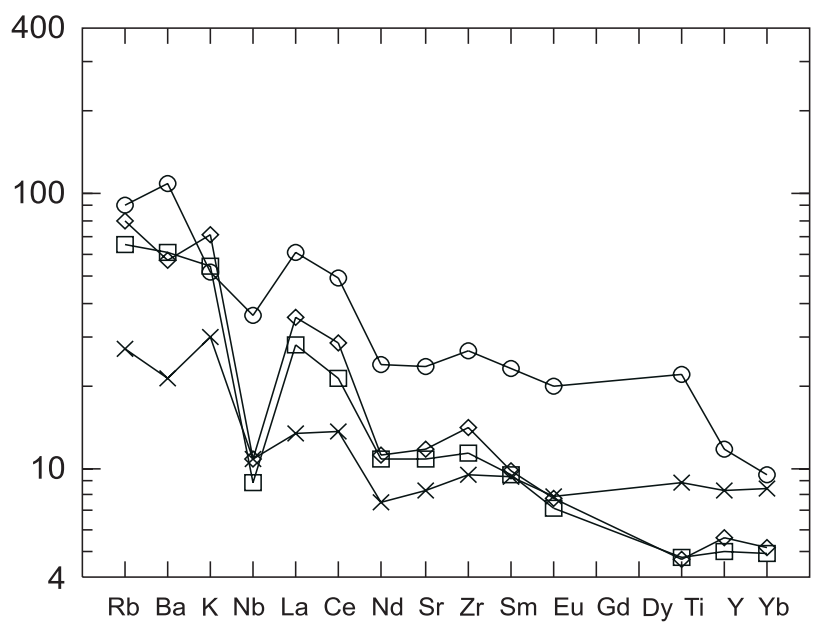

Figura 8. Diagrama da composição média de multielementos normalizados para o manto primitivo segundo os valores de McDonough e Sun (1995). Símbolos como na Figura 4. de partição utilizados nesses modelos de fusões encontramse nos trabalhos de Bossi et al. (1993). A amostra mais primitiva que é dos anfibolitos $A_{1}$ com mg\# de 0,45 não pode ser considerada como magma primário cujo valor de mg\# seria 0,74 - 0,80 (Jaques e Green, 1979; Jaques e Green, 1980; Takahashi e Kushiro, 1983; Bossi et al., 1993). Portanto, a composição primária destes diques foi calculada assumindo $50 \%$ de fracionamento da fonte mantélica, considerando-se as proporções relativas de olivina, clinopiroxênio e plagioclásio respectivamente $20 \%, 50 \%$ e $30 \%$. Cálculos semelhantes ocorreram na literatura (Bossi et al., 1993).

A composição mineral usada no modelo do tipo granada peridotito é $60 \%$ de olivina, $25 \%$ de ortopiroxênio, $10 \%$ de clinopiroxênio e 5\% de granada (Figura 11). O modelo de manto a espinélio peridotito é apresentado na Figura 12 para comparação. A composição modal usada para este modelo é $51 \%$ de olivina, $20 \%$ de ortopiroxênio, $23 \%$ de clinopiroxênio e $6 \%$ de espinélio. Nestas figuras, observam-se, em ambos os modelos, que o conteúdo de LILE ( $\mathrm{Rb}, \mathrm{Ba}, \mathrm{K}$ ), de terras raras leves ( $\mathrm{La}, \mathrm{Ce}$ ), nos gabronoritos e anfibolitos, e de $\mathrm{Nb}, \mathrm{Ti}, \mathrm{Nd}$, $\mathrm{Sm}, \mathrm{Y}$ e $\mathrm{Yb}$ nos anfibolitos refletem porcentagens de fusão inferiores às admitidas como mínimas para produção de líquidos toleíticos, ou seja, ao redor de 10 a 15\% (Kushiro, 2001). Nos gabros esse comportamento é ainda mais radical, pois praticamente todos os elementos incompatíveis e as terras raras refletem o mesmo fenômeno. Isto implica em admitir-se, para todas as suítes enriquecimento mantélico ou contaminação crustal, cujas influências seriam máximas na suíte gabróica. A observação desses diagramas é, à semelhança dos anteriores (Figuras 6, 7, 8, 9 e 10) compatível com a sugestão de

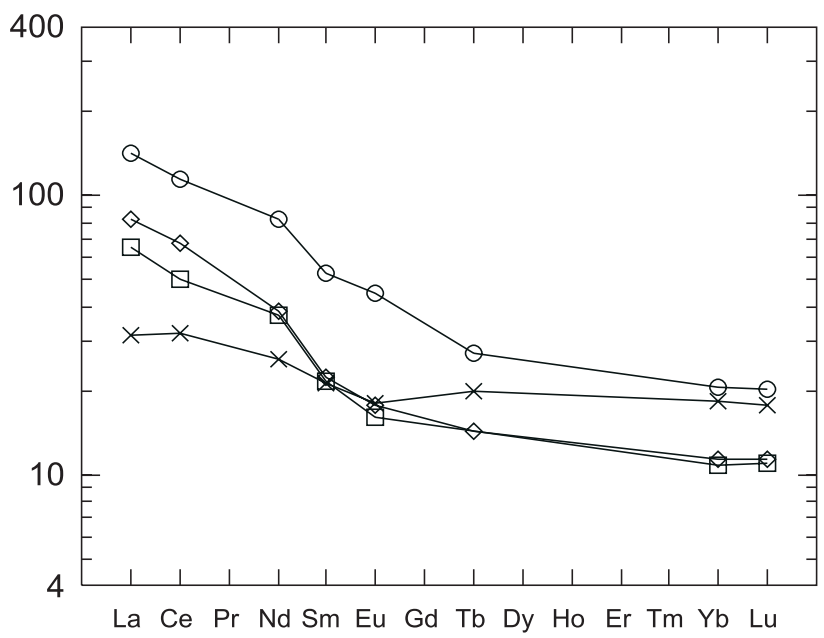

Figura 9. Diagrama da composição média dos elementos terras raras normalizados pelos valores de Boynton (1984). Símbolos como na Figura 4. 
origem dos diversos grupos a partir de fontes distintas. Os gabros, por exemplo, não poderiam ser gerados a partir dessa mesma fonte que originou os gabronoritos, pois seriam necessárias fusões inferiores a $10 \%$ o que é incompatível com formação de magmas toleíticos. Também os padrões dos anfibolitos são diferentes das dos gabros e gabronoritos, nestas e nas figuras já citadas.

\section{AMBIENTE TECTÔNICO E CONSIDERAÇÕES FINAIS}

Durante os últimos 15 anos grande número de diagramas discriminantes foram propostos para identificação de ambientes geotectônicos. Tais diagramas utilizam elementos maiores, menores e traços (Wilson, 1989). Para elucidar os ambientes tectônicos das rochas básicas são utilizados

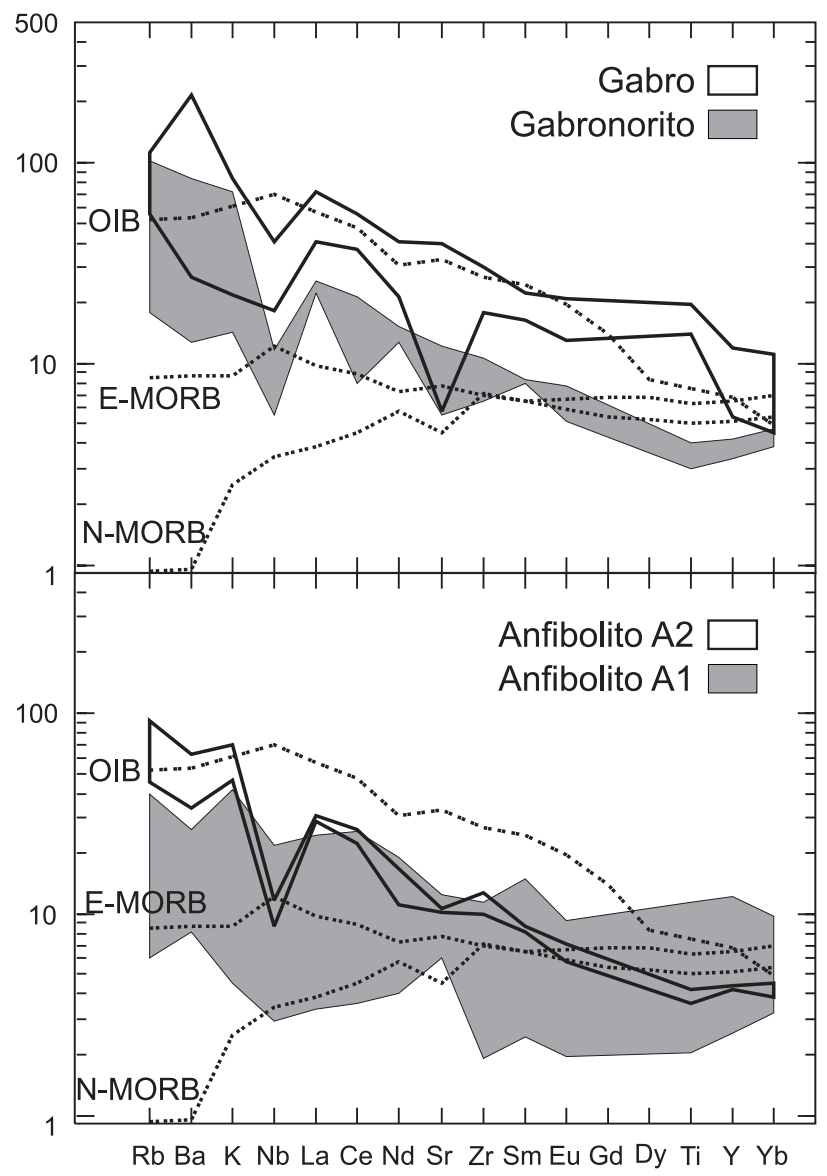

Figura 10. Diagrama de multi-elementos normalizados para o manto primitivo segundo os valores de McDonough e Sun (1995). Os padrões OIB, E-MORB e N-MORB (McDonough e Sun, 1995) são apresentados para efeito de comparação. principalmente Pearce e Cann (1973), Floyd e Winchester (1975), Wood, Joron e Treil (1979), Pearce (1982) e Mullen (1983) entre outros. Entretanto, a heterogeneidade mantélica, observável também em escalas bastante modestas e causadas por fenômenos metassomáticos e contaminantes impedem a utilização indiscriminada de tais diagramas, como apresentado por alguns autores (e.g. Piccirillo et al., 1988; Correia e Girardi, 1989), fato também observado mais recentemente nos diques máficos de Goiás (e.g. Corrêa da Costa e Girardi, 2005).

Com a finalidade de se determinar o provável ambiente tectônico das rochas máficas da região de Candeias, Campo Belo e Santo Antônio do Amparo, os dados geoquímicos dos litotipos estudados foram comparados com os de rochas basálticas de outras regiões do Craton São Francisco (e.g. Carneiro, 1990; Oliveira, 1993; Bastos Leal et al., 1994; Menezes Leal et al., 1995; Pinese, 1997; Maniese e Oliveira, 1997; Bellieni et al., 1995, 1998; Carneiro et al., 1998a), do Bloco Arqueano de Goiás (e.g. Correa da Costa e Girardi, 2005; Corrêa da Costa, Girardi, Teixeira, 2005), do Craton Amazônico (Rivalenti et al., 1998) e do Craton Rio de La Plata (Mazzucchelli et al., 1995; Iacumin et al., 2001). Vale ressaltar, que devido à enorme quantidade de dados geoquímicos, foi feita uma comparação apenas dos litotipos de maior semelhança com os deste trabalho.

A Figura 13 mostra a comparação entre o padrão de elementos incompatíveis dos gabros e gabronoritos com o padrão de outras suítes basálticas. O campo de composição de gabros apresenta semelhanças com os campos composicionais dos diques de Carajás ATi no Craton Amazônico, dos diques de Salvador ATi no Craton São Francisco, e dos diques de Goiás ATi no Bloco Arqueano de Goiás; diferindo destes por serem de modo geral mais enriquecidos principalmente em LILE, La, Ce, Nd e Sr. Os gabronoritos assemelham-se aos padrões de Salvador BTi e Goiás BTi, diferindo destes principalmente por serem mais ricos em LILE e mais pobres em terras raras pesadas. Ambas as litologias são também semelhantes aos basaltos mesozóicos da Bacia do Paraná, sendo que a principal diferença é a maior quantidade de terras raras pesadas nestes últimos.

O padrão de elementos incompatíveis dos anfibolitos também foi comparado com o padrão das suítes basálticas apresentadas na Figura 14. As maiores semelhanças dos anfibolitos $\mathrm{A}_{1}$ e $\mathrm{A}_{2}$ ocorrem respectivamente com os diques Goiás BTi e Goiás ATi.

As similaridades observadas entre os diques máficos de Carajás no Craton Amazônico, de Salvador, no Craton São Francisco e de Crixás-Goiás no Bloco Arqueano de Goiás, classificados como intracratônicos (e.g. Rivalenti et al., 1998; Bellieni et al., 1995; Corrêa da Costa, Girardi, Teixeira, 2005), e os litotipos de Candeias, Campo Belo e Santo Antônio do 
Amparo permitem sugerir, para os últimos, ambiente continental intracratônico.

No que concerne às considerações finais pode-se dizer que o enxame de diques em questão resultou de magmatismo fissural que invadiu a porção meridional do Craton São Francisco, representado pelo Complexo Metamórfico Campo Belo, estável desde o Mesoarqueano. As concentrações e o comportamento geoquímico dos elementos maiores, menores e traços indicam que os quatro grupos de rochas denominados Anfibolitos $\mathrm{A}_{1}$, Anfibolitos $\mathrm{A}_{2}$,

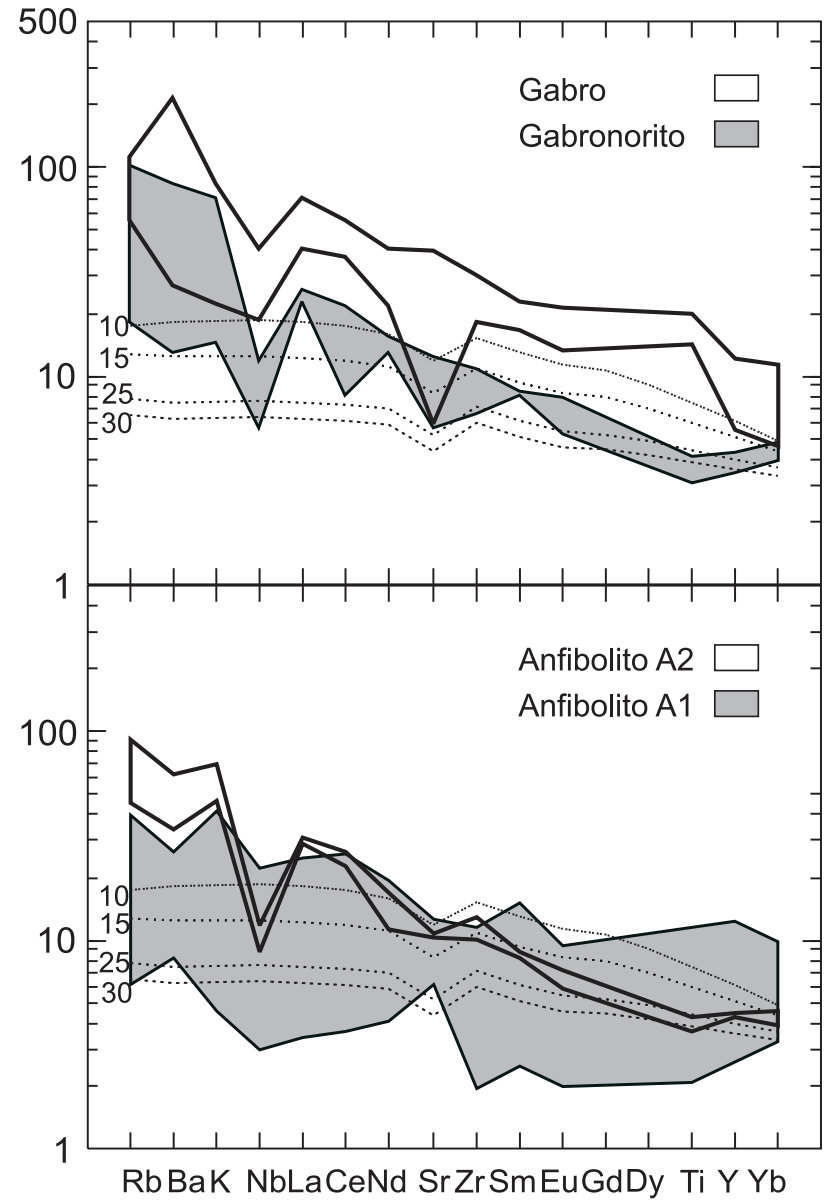

Figura 11. Padrão de elementos traços incompatíveis normalizados para o manto primitivo (McDonough e Sun, 1995) dos gabros, gabronoritos e anfibolitos. As linhas de $10 \%, 15 \%, 25 \%$ e $30 \%$ correspondem à fusão de uma fonte do tipo granada peridotito (McDonough e Sun, 1995) com $50 \%$ de fracionamento (olivina 20, clinopiroxênio 50 e plagioclásio 30). Coeficiente de partição segundo Bossi et al. (1993).
Gabronoritos e Gabros pertencem a suítes magmáticas diversas, todas variavelmente enriquecidas em elementos incompatíveis e terras raras, o que sugere ação de fonte mantélica heterogênea enriquecida e/ou contaminação crustal na formação desses magmas. A solução desse problema requer o uso de dados isotópicos, utilizáveis também para a determinação da idade do enxame. Nesse aspecto vale ressaltar as similaridades com os diques básicos existentes em Lavras, a cerca de $60 \mathrm{~km}$, datados em 1,9 Ga (Pinese, 1997).

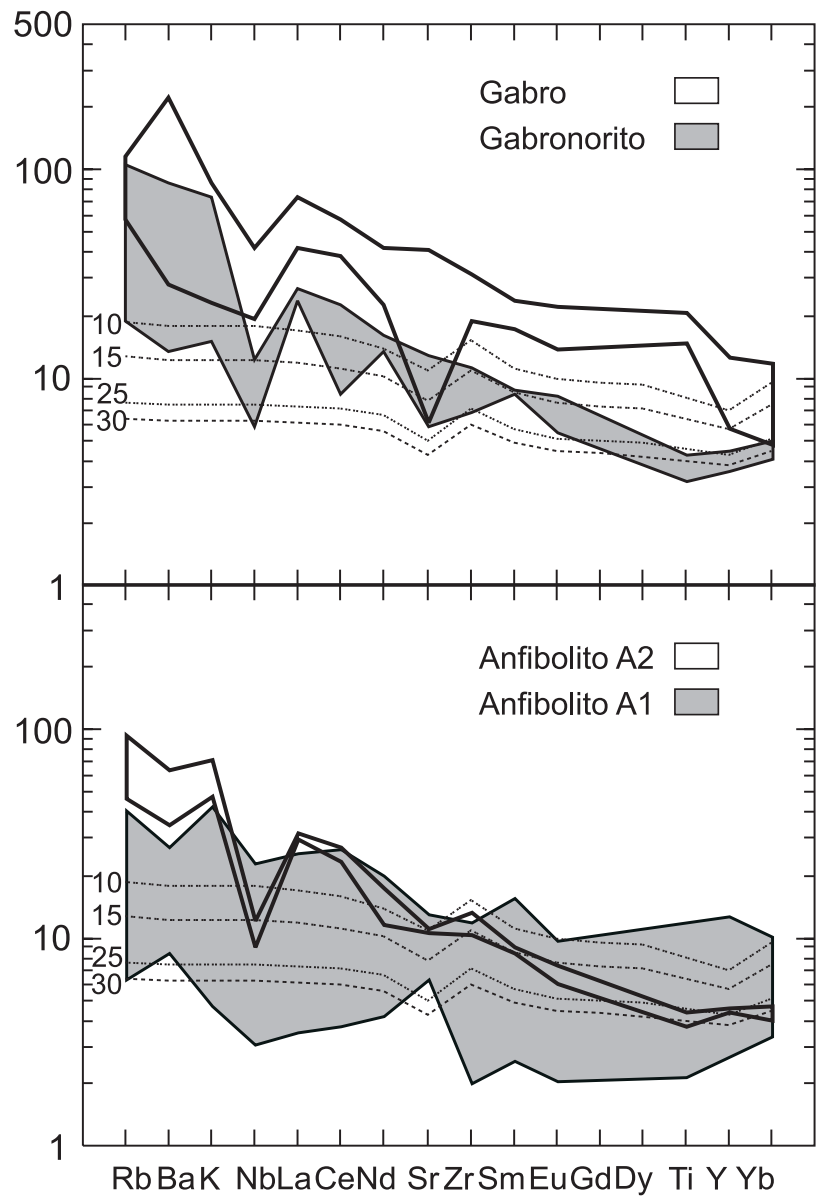

Figura 12. Padrão de elementos traços incompatíveis normalizados para o manto primitivo (McDonough e Sun, 1995) dos gabros, gabronoritos e anfibolitos. As linhas de $10 \%, 15 \%, 25 \%$ e $30 \%$ correspondem à fusão de uma fonte do tipo espinélio peridotito (McDonough e Sun, 1995) com $50 \%$ de fracionamento (olivina 20, clinopiroxênio 50 e plagioclásio 30). Coeficiente de partição segundo Bossi et al. (1993). 


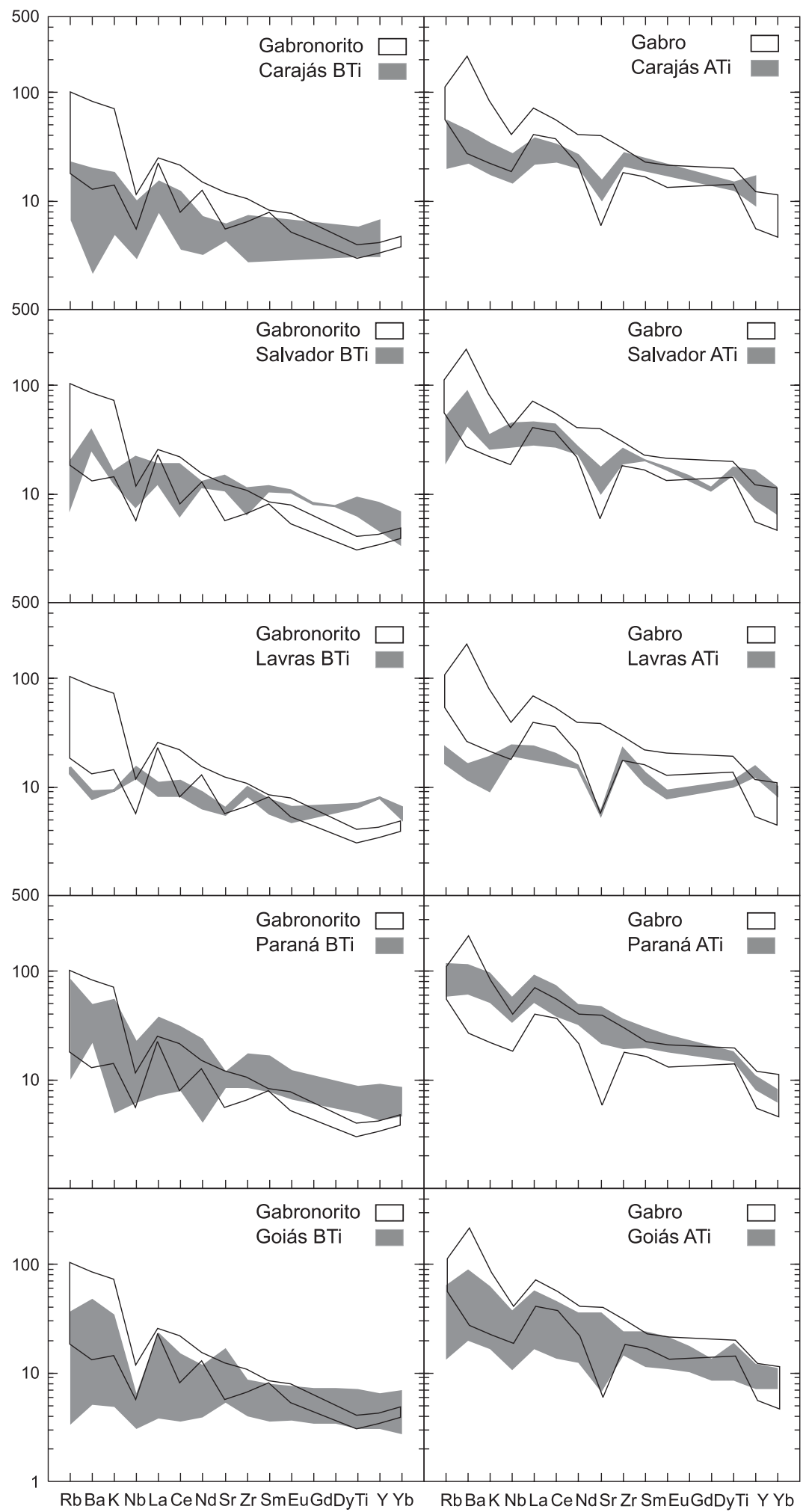

Figura 13. Diagramas multi-elementar normalizados para o manto primitivo segundo McDonough e Sun (1995), dos gabros e gabronoritos comparados com litotipos máficos do Craton Amazônico (Carajás), Craton São Francisco (Salvador, Lavras), Bloco Arqueano de Goiás e basaltos da Bacia do Paraná. BTi - baixo titânio; ATi - alto titânio. 


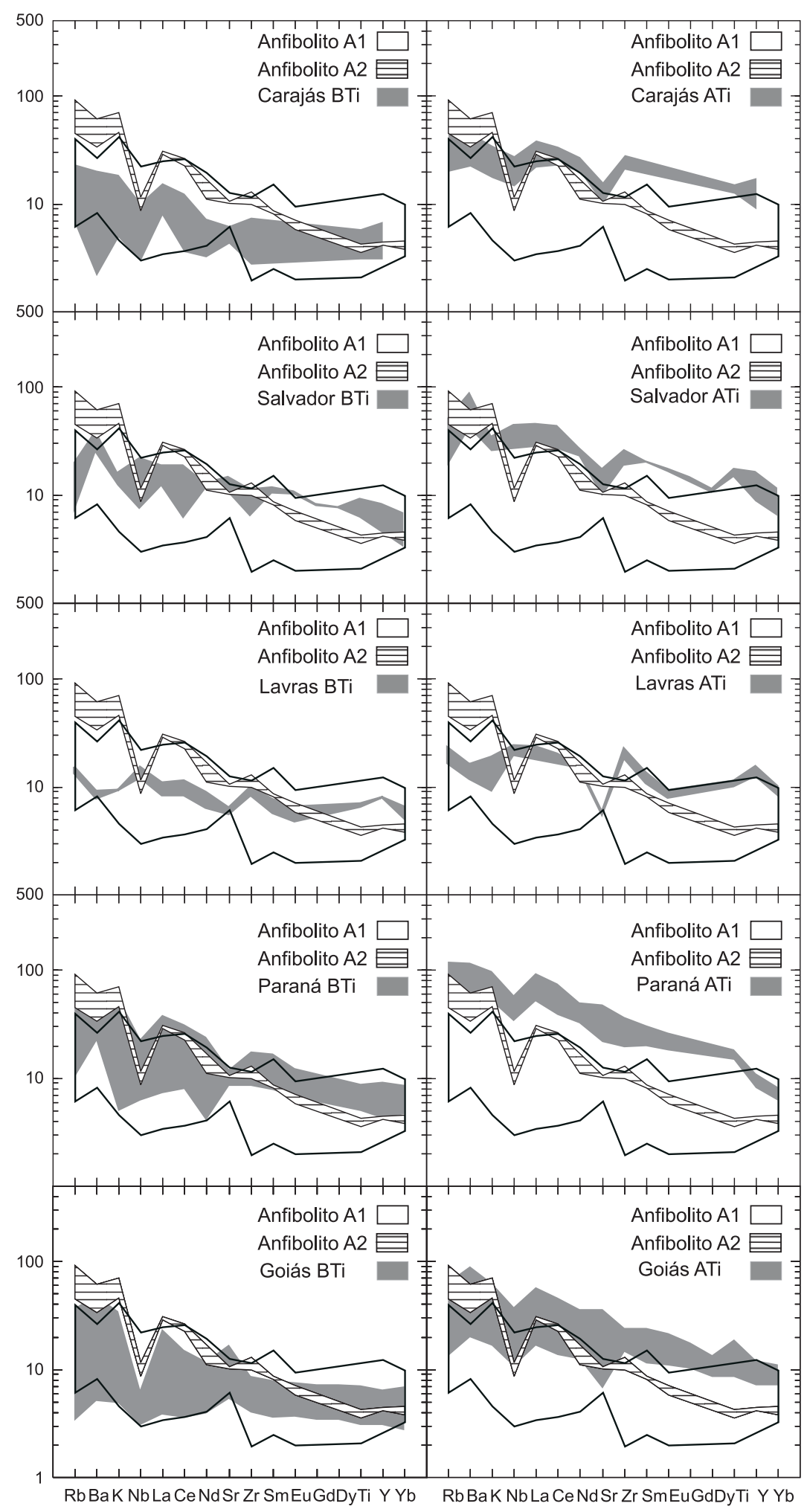

Figura 14. Diagramas multi-elementar normalizados para o manto primitivo segundo McDonough e Sun (1995), dos anfibolitos $A_{1}$ e $A_{2}$ comparados com litotipos máficos do Craton Amazônico (Carajás), Craton São Francisco (Salvador, Lavras), Bloco Arqueano de Goiás e basaltos da Bacia do Paraná. BTi - baixo titânio; ATi - alto titânio. 


\section{AGRADECIMENTOS}

Os autores gostariam de prestar seus agradecimentos ao CNPq, à FAPESP, à FAPEMIG (Proc. Cex 827/96) e à FAPEMAT pelos incentivos financeiros e ao laboratório (LOPAG-DEGEO/EM/UFOP) pela preparação das amostras.

\section{REFERÊNCIAS BIBLIOGRÁFICAS}

BASTOS LEAL, L. R.; TEIXEIRA, W.; PICCIRILO, E. M.; MENEZES LEAL, A. B.; GIRARDI, V. A. V. Geocronologia $\mathrm{Rb} / \mathrm{Sr}$ e K/Ar do enxame de diques máficos de Uauá, Bahia (Brasil). Geochimica. Brasiliensis, v. 8, p. 99-114, 1994.

BELLIENI, G.; PETRINI, R.; PICCIRILLO, E. M.; BRITO, C. M.; FIGUEIREDO, A. M. G.; MARQUES, L. S.; DE MIN, A.; MELFI, A. J. Petrogenesis and tectonic significance of the Late Proterozoic unmetamorphosed mafic dyke swarms from the Salvador area (NE Brazil). Neues Jahrbuch fur Mineralogie. Abhabdlungen, v. 173, p. 327-350. 1998.

BELLIENI, G.; PICCIRILLO, E. M.; PETRINI, R.; GIRARDI, V. A.V.; MENEZES LEAL, A. B.; TEIXEIRA, W.; BASTOS LEAL, L. R.; DE MIN, A.; COMIN CHIARAMONTI, P.; TANNER DE OLIVEIRA, M. A. F. Petrological and Sr-Nd evidence bearing on Early Proterozoic magmatic events of the subcontinental mantle: Sao Francisco Craton (Uauá, NEBrazil). Contributions to Mineralogy and Petrology, v. 122, p. 252-261, 1995.

BELLIENI, G; PETRINI, R.;PICCIRILLO,E. M.; CAVAZZINI, G.; CIVETTA, L.; COMIN CHIARAMONTI, P.; MELFI, A.J.; BERTOLO, S.; DE MIN, A. Proterozoic mafic dyke swarms of the Sao Francisco Craton (SE-Bahia State, Brazil): petrology and $\mathrm{Sr}-\mathrm{Nd}$ isotopes. European Journal of Mineralogy, v. 3, p. 429-449, 1991.

BELLIENI, G.; COMIN CHIARAMONTI, P.; MARQUES, L. S.; MELFI, A. J.; PICCIRILLO, E. M.; NARDY, A .J. R.; ROISENBERG, A. High- and low- $\mathrm{TiO}_{2}$ flood basalts from the Paraná plateau (Brazil): petrology and geochemical aspects bearing on their mantle origin. Neues Jahrbuch fur Mineralogie. Abhabdlungen, v. 150, p. 273-306, 1984.

BESWICK, A. E. Some geochemical aspects of alteration and genetic relations in komatiitic suites. In: ARDNT, N. T.; NESBITT, E. G. Komatiites. London: George Allen and Unwin, 1982. p. 283-308.

BOSSI, J.; CAMPAL, N.; CIVETTA, L.; DEMARCHI, G.; GIRARDI, V. A. V. MAZZUCCHELLI, M.; NEGRINI, L.; RIVALENTI, G.; FRAGOSO CESAR, A. R. S.; SINIGOI, S.;
TEIXEIRA, W.; PICCIRILLO, E.M.; MOLESINI, M. Early Proterozoic dike swarms from western Uruguay: geochemistry, Sr-Nd isotopes and petrogenesis. Chemical Geology, v. 106, p. 263-277, 1993.

BOYNTON, W. V. Cosmochemistry of rare earth elements: meteorite studies. In: HENDERSON, P. Rare earth element geochemistry. Amsterdan: Elsevier, 1984. p. 63-114.

CARNEIRO, M. A.; TEIXEIRA, W.; CARVALHO JR., I. M. DE; PIMENTEL, M. M.; OLIVEIRA, A. H. DE Comportamento dos Sistemas Sm-Nd e Rb-Sr da Seqüência Máfico-Ultramáfica Ribeirão dos Motas (Arqueano), Craton São Francisco Meridional: Evidências de Enriquecimento Mantélico e Fracionamento Isotópico. Geologia USP. Série Cientifica, v. 4, p. 13-26, 2004.

CARNEIRO, M. A.; CARVALHO JR., I. M. DE; TEIXEIRA, W. Petrologia, Geoquímica e Geocronologia dos Diques Máficos do Complexo Metamórfico Bonfim Setentrional (Quadrilátero Ferrífero) e suas implicações na evolução crustal do Craton São Francisco Meridional. Revista Brasileira de Geociências, v. 28, p. 29-44, 1998a.

CARNEIRO, M .A.; TEIXEIRA, W.; CARVALHO JR., I. M. DE; FERNANDES, R. A. Ensialic Tectonic setting of the Archaean Rio das Velhas Greenstone Belt: $\mathrm{Nd}$ and $\mathrm{Pb}$ isotopic evidence from the Bonfim Metamorphic Complex, Quadrilátero Ferrífero, Brasil. Revista Brasileira de Geociências, v. 28, p. 189-200, 1998 b.

CARNEIRO, M. A.; TEIXEIRA, W.; NALINI JÚNIOR, A.; OLIVEIRA, A. H. de; CARVALHO JÚNIOR, I. M. de. Archean ultramafic-mafic magmatism in the southern São Francisco Craton (Campo Belo Complex): Preliminary petrographic and geochemical results. In: SIMPÓSIO DE TERRENOS ARQUEANOS DA PLATAFORMA SULAMERICANA, 1996, Brasília. Anais... Brasília: SBG, 1996. p. 32 e 33 .

CARNEIRO, M. A. Características petrográficas e geoquímicas dos diques Máficos da porção setentrional do complexo Metamórfico do Bonfim, Quadrilátero Ferrífero, Minas Gerais. In: WORKSHOP DIQUES MÁFICOS DO BRASIL, 2., 1990, São Paulo. Boletim Especial: Trabalhos Apresentados. São Paulo: IUGS, 1990. p. 27-32.

CARVALHO JÚNIOR., I. M. de; CARNEIRO, M. A.; SUÍTA, M. T. de F.; TEIXEIRA, W. Anfibólio intercúmulus na Seqüência Acamadada do Ribeirão dos Motas: um modelo Petrogenético para sua Origem. In: SIMPÓSIO DE GEOLOGIA DE MINAS GERAIS, 9., 1997, Ouro Preto. 
Anais... Ouro Preto: SBG, 1997. v. 14, p. 38-39.

CONDIE, K. C.; BOBROW, D. J.; CARD, K. D. Geochemistry of Precambrian Mafic Dyke from Southern Superior Province of the Canadian Shield. Special Paper Geological Association of Canada, v. 34, p. 95-108, 1987.

CORRÊA DA COSTA, P. C., GIRARDI, V. A. V., Petrology, geochemistry and Sr-Nd isotopes of the Paleoproterozoic dikes from the Goiás - Crixás Archean Block, Goiás State, Brazil. Revista Brasileira de Geociências, v. 35, p. 135-150, 2005.

CORRÊADACOSTA, P.C.; GIRARDI, V.A. V.; TEIXEIRA, W. ${ }^{40} \mathrm{Ar} /{ }^{39} \mathrm{Ar}$ geochronology of the Goiás-Crixás dyke swarm, Central Brazil: further evidence of the NeoarcheanPaleoproterozoic tectonic boundary in South America and Nd-Sr signature of the subcontinental mantle throughout time. International Geology Review, 2005. (No prelo).

CORREAA DA COSTA, P. C.; CARNEIRO, M. A.; FERNANDES, R. A. Petrologia e Geoquímica dos Diques Máficos da Região de Candeias - Campo Belo - Santo Antônio do Amparo (MG). Porção Meridional do Craton São Francisco. In: SIMPÓSIO DE GEOLOGIA DE MINAS GERAIS, 11., 2001, Belo Horizonte Anais... Belo Horizonte: SBG 2001. 1 CD-ROM.

CORRÊA DA COSTA, P. C. Episódios de Formação de Crosta Continental Arqueana no Craton São Francisco Meridional: Um exemplo a partir da região de Candeias Campo Belo, MG. 1999. Dissertação (Mestrado) Departamento de Geologia, Universidade Federal de Ouro Preto, Ouro Preto.

CORRÊA GOMES, L. C. Província de Diques Máficos do Estado da Bahia: mapas, estágio atual do conhecimento e evolução temporal. Salvador: Governo do Estado da Bahia, $1996.114 \mathrm{p}$.

CORREIA, C. T. ; GIRARDI, V. A. V. Estudo Geoquímico e Petrológico dos Anfibolitos da Região de Cássia, MG Revista Brasileira de Geociências, v. 19, p. 37-50, 1989.

COUTO, J. G. P.; TEIXEIRA, W.; CORDANI, U. G. Considerações sobre as principais épocas de faturamento do Craton São Francisco, com base em datações K-Ar de rochas básicas. In: SIMPÓSIO DE GEOLOGIA DE MINAS GERAIS, 2., 1983, Belo Horizonte. Anais... Belo Horizonte: SBG, 1983. v. 3, p. 38-49.

FERNANDES, R. A. Etapas de formação de Crosta
Continental (do Mesoarqueano ao Mesoproterozóico) no Craton São Francisco Meridional. 2001. Dissertação (Mestrado) - Departamento de Geologia, Universidade Federal de Ouro Preto, Ouro Preto.

FERNANDES, R. A.; Carneiro, M. A.; Teixeira, W. O Metamorfismo das Rochas da Região de Santana do Jacaré, MG. In: SIMPÓSIO DE GEOLOGIA DE MINAS GERAIS, 9., 1997, Ouro Preto. Anais... Ouro Preto: SBG, 1997. v. 14 , p. $45-46$.

FLOYD, P. A.; WINCHESTER, J. A. Magma type and tectonic setting discrimination using immobile elements. Earth and Planetary Science Letters, v. 27, p. 211-218, 1975.

HALLS, H. C.; FAHRIG, W. H. Mafic Dykes Swarms. Special Paper Geological Association of Canada, v. 34, p. 503, 1987.

HALLS, H. C. The importance and potential of mafic dyke swarms in studies of geodynamic processes. Geoscience Canada, v. 9, n. 3, p. 145-154, 1982.

IACUMIN, M.; DE MIN, A.; PICCIRILLO, E. M.; BELLIENI, G. Source mantle heterogeneity and its role in the genesis of Late Archaean-Proterozoic (2.7-1.0 Ga) and Mesozoic (200 and $130 \mathrm{Ma}$ ) tholeiitic magmatism in the South American Platform. Earth-Science Reviews, v. 62, p. 365-397, 2003.

IACUMIN, M.; PICCIRILLO, E. M.; GIRARDI, V. A. V.; TEIXEIRA, W.; BELLIENI, G.; ECHEVESTE, H.; FERNANDEZ, R.; PINESE, J. P. P.; RIBOT, A. Early Proterozoic Calc-Alkaline and Middle Proterozoic Tholeiitic Dike Swarms from Central-Eastern Argentina: Petrology, Geochemistry, Sr-Nd Isotopes and Tectonic Implications. Journal of Petrology, v. 42, p. 2109-2143, 2001.

IRVINE, I. N.; BARAGAR, W. R. A. A guide to the chemical classification of the common volcanic rocks. Canadian Journal Earth Sciences, v. 8, p. 523-548, 1971.

JAQUES, A. L.; GREEN, D. H. Anhydrous Melting of Peridotite at $0-15 \mathrm{~Kb}$ Pressure and the Genesis of Tholeiitic Basalts. Contributions to Mineralogy and Petrology, v. 73, p. 287-310, 1980.

JAQUES, A. L.; GREEN, D. H. Determination of liquid compositions in high-pressure melting of peridotite. American Mineralogist, v. 64, p. 1312-1321, 1979.

KUSHIRO, I. Partial Melting Experiments on Peridotite and 
Origin of Mid-Ocean Ridge Basalt. Annual Review of Earth and Planetary Sciences, v. 29, p. 71-107, 2001.

LE BAS, M. J.; LE MAITRE, R. W.; STRECKEISEN, A.; ZANETTIN, B. A chemical classification of volcanic rocks based on total alkali-silica diagram. Journal of Petrology, v. 27, p. $745-750,1986$.

MACHADO, N.; CARNEIRO, M. A. U-Pb evidence of late Archean tectonothermal activity in the southern São Francisco shield, Brazil. Canadian Journal Earth Sciences, v. 29, p. 2341-2346, 1992.

MANIESI, V.; OLIVEIRA, M. A. F. Petrologia das Soleiras de Diabásio de Reserva e Salto do Itararé, PR. Geochimica Brasiliensis, v. 11, p. 153-169, 1997.

MAZZUCCHELLI, M.; RIVALENTI, G.; MENEZES LEAL, A. B.; GIRARDI, V. A. V.; BRITO NEVES, B. B.; TEIXEIRA, W. Petrology of metabasaltic dykes in the Diamantina region, Minas Gerais, Brazil. Periodico di Mineralogia, v. 70, p. 231-254, 2000 .

MAZZUCCHELLI, M.; RIVALENTI, G.; PICCIRILLO, E.; GIRARDI, V.A. V.; CIVETTA, L. Petrology of the Proterozoic mafic dyke swarms of Uruguay and constraints on their mantle source composition. Precambrian Research, v. 74, p. 177-194, 1995.

MCDONOUGH, W. F.; SUN, S. S. The composition of the Earth. Chemical Geology, v. 120, p. 223-253, 1995.

MENEZES LEAL,A. B.; GIRARDI, V.A. V.; BASTOS LEAL, L. R. Petrologia e Geoquímica do Magmatismo Básico da Suíte Básica Apoteri, Estado de Roraima - Brasil. Geochimica Brasiliensis, v. 14, p. 155-174, 2000.

MENEZES LEAL, A. B.; BELLIENI, G.; GIRARDI, V.A. V.; BASTOS LEAL, L. R.; TEIXEIRA, W.; PICCIRILLO, E. M. Contribuição ao Estudo Petrológico e Geoquímico dos Enxames de Diques Máficos de Uauá, Bahia, Brasil. Geochimica Brasiliensis, v. 9, p. 61-90, 1995.

MULlEN, E. D. $\mathrm{MnO} / \mathrm{TiO}_{2} / \mathrm{P}_{2} \mathrm{O}_{5}$ : a minor element discriminant for basaltic rocks of oceanic environments and its implications for petrogenesis. Earth and Planetary Science Letters, v. 62, p. 53-62, 1983.

NOCE, C.M., TEIXEIRA, W., QUÉMÉNEUR, J.J.G., VERIDIANA, T.S.M., BOLZACHINI, É. Isotopic signatures of Paleoproterozoic granitoids from the southern São Francisco Craton and implications for the evolution of the
Transamazonian Orogeny. Journal of American Earth Sciences, v.13, p. 225-239, 2000.

NOCE, C. M. Geocronologia dos eventos magmáticos, sedimentares e metamórficos na região do Quadrilátero Ferrífero, Minas Gerais. 1995. Tese (Doutorado) - Instituto de Geociências, Universidade de São Paulo, São Paulo.

OLIVEIRA, A. H.; CARNEIRO, M. A. Campo Belo Metamorphic Complex: Tectonic Evolution of an Archaean sialic crust of the southern São Francisco Craton in Minas Gerais (Brazil). Anais da Academia Brasileira de Ciências, v. 73, p. 397-415, 2001.

OLIVEIRA, A. H. de; CORRÊA DA COSTA, P. C. C.; CARNEIRO, M. A.; NALINI JUNIOR, H. A. Feições lineares e suas implicações em um segmento crustal Arqueano do Craton São Francisco Meridional. In: CONGRESSO BRASILEIRO DE GEOLOGIA, 40., 1998, Belo Horizonte. Anais... Belo Horizonte: SBG, 1998. p. 58.

OLIVEIRA, E. P. Diques toleíticos, noríticos e piroxenitos no enxame de diques de Uauá, Bahia: Evidências geoquímicas de heterogeneidades no manto Proterozóico inferior do Craton do São Francisco. In: CONGRESSO BRASILEIRO DE GEOQUÍMICA, 4., 1993, Brasília. Boletim de resumos... Brasília: Sbgq, 1993. p. 5-7.

PEARCE, J. A.; CANN, J. R. Tectonic setting of basic volcanic rocks determined using trace element analyses. Earth and Planetary Science Letters, v. 19, p. 290-300, 1973.

PEARCE, J. A. Trace element characteristics of lavas from destructive plate boundaries. In: THORPE, R. S. Andesites. Orogenic andesites and related rocks. Chichester: J. Wiley, 1982. p. 525-547.

PEARCE, T. H. A contribution to the theory of variations diagrams. Contributions to Mineralogy and Petrology, v. 19, p. $42-57,1968$.

PICCIRILLO,E.M.; BELLIENI, G; COMIN-CHIARAMONTI, P.; ERNESTO, M.; MELFI, A. J.; PACCA, I. G.; USSAMI, N. Significance of the Paraná flood volcanism in the disruption of western gondwanaland. In: PICCIRILO, E. M.; MELFI, A. J. The Mesozoic Flood Volcanism of the Paraná Basin: petrogenetic and geophysical aspects. São Paulo: IAG, 1988. p. 285-295.

PINESE, J. P. P. Geoquímica, Geologia Isotópica e Aspectos petrológicos dos Diques Máficos Pré-Cambrianos da Região de Lavras (MG), porção sul do Craton São 
Francisco. 1997. Tese (Doutorado) - Instituto de Geociências, Universidade de São Paulo, São Paulo.

RIVALENTI, G; MAZZUCCHELLI, M.; GIRARDI, V.A. V.; CAVAZZINI, G; FINATTI, C.; BARBIERI, M. A.; TEIXEIRA, W. Petrogenessis of the Paleoproterozoic basalt - andesit rhyolite dyke association in the Carajás region. Amazonian craton. Lithos, v. 43, p. 235-265, 1998.

SIAL, A. M.; OLIVEIRA, E. P.; CHOUDHURI, A. Mafic dykes swarms of Brazil. Special Paper Geological Association of Canada, v. 34, p. 467-481, 1987.

TAKAHASHI, E. \& KUSHIRO, I. Melting of dry peridotite at high pressures and basalt magma genesis. American Mineralogist, v. 68, p. 859-879, 1983.

TARNEY, J.; WEAVER, B. L. Geochemistry and Petrogenesis of Early Proterozoic dyke swarms. Special Paper Geological Association of Canada, v. 34, p. 81-94, 1987.

TEIXEIRA, W., SABATÉ, P., BARBOSA, J., NOCE, C. M., AND CARNEIRO, M. A. Archean and Paleoproterozoic tectonic evolution of the São Francisco Craton. In: INTERNATIONAL GEOLOGICALCONGRESS, 31., 2000, Rio de Janeiro. Rio de Janeiro: CPRM, 2000., p. 101-135. 1 CD-ROM.

TEIXEIRA, W.; CORDANI, U. G.; NUTMAN, A. P.; SATO, K. Polyphase Archean evolution in the Campo Belo Metamorphic Complex. Southern São Francisco Craton (Brazil): SHRIMP U-Pb zircon evidence. Journal of South America Earth Science, v. 11, p. 279-289, 1998.

TEIXEIRA, W. The Proterozoic mafic dyke Swarms and alkaline intrusions in the Amazonian Craton, South America, and their tectonic evolution based on $\mathrm{Rb}-\mathrm{Sr}, \mathrm{K}-\mathrm{Ar}$ and $\mathrm{Ar}$ Ar geochronology. In: PARKER, A. J.; RICKWOOD, P. C.; TUCKER, D. H. Mafic Dykes and Emplacement Mechanisms. Rotterdam: Balkema, 1990. v. 23, p. 285-293.

TEIXEIRA, W. Mafic Dykes in the southern part of the São Francisco Craton: A tectonic review based on K/Ar geochronology. Boletim IG-USP. Série Científica, v. 20, p. 25-30, 1989.

TEIXEIRA, W. Geochronology of the southern part of the São Francisco Craton. Revista Brasileira de Geociências, v. 12 , p. 268-277, 1982.

WILSON, M. Igneous Petrogenesis. London: Kluwer Academic Publishes, 1989. $465 \mathrm{p}$.
WOOD, D. A.; JORON, J. L.; TREUIL, M. A re-appraisal of the use of trace elements to classify and discriminate between magma series erupted in different tectonic settings. Earth Planetary Science Letters, v. 45, p. 326-336, 1979. 